\title{
Dynamics of Wealth and Consumption: New and Improved Measures for U.S. States
}

March 3, 2012

Xia Zhou ${ }^{1} \quad$ Christopher D. Carroll ${ }^{2}$

\begin{abstract}
Case, Quigley, and Shiller (2005) persuasively argue that the well-known conceptual difficulties in measuring aggregate "wealth effects" might be lessened by the use of state-level data. Unfortunately, the data required for a convincing implementation of their idea have been either virtually nonexistent (for financial wealth) or of questionable quality (for consumption). Our main contributions are to provide the first directly observed panel data on financial wealth at the state level, and to construct improved measures of state-level spending growth. Using these data, we estimate rudimentary "wealth effects" regressions that find a strong relationship between twice-lagged housing wealth growth and current spending growth, but we find no relationship between lagged financial wealth growth and current spending growth.
\end{abstract}

Keywords housing wealth effect, financial wealth effect

JEL codes E2, G1

Forthcoming, Berkeley Electronic Journal of Macroeconomics

PDF: http://econ.jhu.edu/people/ccarroll/papers/zcWandCdynByState.pdf

Slides: http://econ.jhu.edu/people/ccarroll/papers/zcWandCdynByState-Slides.pdf

Web: http://econ.jhu.edu/people/ccarroll/papers/zcWandCdynByState/

Archive: http://econ.jhu.edu/people/ccarroll/papers/zcWandCdynByState.zip

\footnotetext{
${ }^{1}$ Zhou: xia_zhou@fanniemae.com, Federal National Mortgage Association, 3900 Wisconsin Ave, Washington, DC $20016 \quad{ }^{2}$ Carroll: ccarroll@jhu.edu, Department of Economics, 440 Mergenthaler Hall, Johns Hopkins University, Baltimore, MD 21218, http://econ.jhu.edu/people/ccarroll, and National Bureau of Economic Research. 


\section{Introduction}

Macroeconomic forecasting models often incorporate a "wealth effect" which asserts that movements in household net worth cause corresponding movements in aggregate consumption. U.S. data showing a striking negative relationship between the wealthto-income ratio and the personal saving rate (see Figure 1) are often presented in support of this proposition, and statistical analysis finds a robust relationship between aggregate wealth movements and subsequent household spending growth. ${ }^{1}$

But a skeptic could find plenty of reasons to doubt that this correlation reflects causation from wealth movements to consumption or saving outcomes. First, the association could reflect simultaneity. For instance, any shock to consumers' optimism or pessimism could have an impact on housing prices, stock prices, and consumption growth in the same direction. Second, endogeneity could also reflect reverse causality of consumption on wealth (for example, a consumption boom might bid up stock prices as expected profits rise). Finally, simple kinds of measurement error could lead to the observed association. For example, suppose that income $Y$ is measured with error. By construction, the personal saving rate, $s=1-C / Y$, will also be mismeasured in the same direction as $Y$. At the same time, the measured wealthincome ratio $W / Y$ will be biased in the opposite direction, generating a spurious negative relationship.

In an effort to get around these problems, a substantial literature has turned to micro data. But household-level data suffer from serious measurement problems. There is a very limited choice of household-level data available for carrying out such studies in the U.S. For instance, the Panel Study on Income Dynamics (PSID) only measures food consumption, while the Consumer Expenditure Survey (CEX) has detailed but noisy data on household expenditures and poor financial information. The Survey of Consumer Finances (SCF) provides no measure of consumption at all.

An alternative approach, one that potentially avoids some of the problems related to both aggregate and household-level data, is to use regional data. First, if there is sufficient variation across regions, the endogeneity problem might be mitigated. For instance, consider a region-specific shock to consumers' confidence, one that might also have a large impact on the consumption behavior of households in the region. However, if a well-integrated stock market exists, this region-specific shock might not have as great an impact on stock prices of persons who live in the region as a corresponding aggregate shock to confidence would have on aggregate stock prices. Therefore, the endogeneity problem between local wealth and local consumption is alleviated to some extent. Furthermore, it can be argued that regional data provides more comprehensive and better measures of the relevant variables than household-

\footnotetext{
${ }^{1}$ See Davis and Palumbo (2001a) for a survey of the literature and standard estimates; Carroll, Otsuka, and Slacalek (2011) reach similar conclusions using a different methodology.
} 
level data. Finally, regional data is more likely to cover a longer time period and therefore allow for richer dynamics.

Case, Quigley, and Shiller (2005) pioneered the estimation of wealth effects using regional data. We improve on their efforts in several ways. Most notably, after showing that CQS used a flawed method to construct state-level financial wealth, we construct a new panel dataset of financial wealth for U.S. states, using anonymous proprietary account-level records of geographic wealth holdings. We will argue that our new financial wealth dataset is much more accurate than existing alternative measures used previously in the literature. Another contribution of this paper is to construct a significantly improved state-level proxy for consumption data. Our two new datasets are then combined to provide new estimates of how household spending changes following movements in stock and housing wealth.

The rest of the paper is organized as follows: Section 2 reviews the related literature; Section 3 discusses the limitations of the currently available state-level consumption and stock wealth datasets; Section 4 describes the newly constructed data; and Section 5 presents the model specification and regression results, then uses those results to calculate the estimated contribution of disparate cross-state housing wealth movements to differences in the runup in consumption spending (prior to 2008) and the subsequent decline (after 2008). Some very rough calculations suggest that only a small portion of the post-2008 decline in spending can be attributed to the effects of housing price declines (though the estimated long lags in the housing wealth effect suggest that spending weakness may continue for some time). Section 6 concludes.

\section{Recent Evidence}

The existing literature on whether the marginal propensity to consume (MPC) differs out of different components of wealth is small. Davis and Palumbo (2001b) compared the stock market wealth effect with the non-stock-market wealth effect using U.S. aggregate data. The results, derived from a cointegration analysis, are, however, sensitive to model specification. The long-run effects of both types of wealth are estimated to be about the same (i.e., 0.06 for stocks and 0.08 for non-stocks) when the level of variables is used. Using logarithms, however, the results show an elasticity for non-stock wealth four times greater than that for stock wealth; this implies that the MPC out of non-stock wealth is at least twice as large as the MPC out of stock wealth. Additionally, using aggregate data (though applying a different method), Carroll, Otsuka, and Slacalek (2011) reported an immediate MPC out of housing wealth of about 1.5 cents and an immediate stock wealth MPC of 0.75 cents. This difference, however, is statistically insignificant.

Levin (1998) appears to be the first study in the U.S. to use household-level data to estimate the differential effect of housing and stock wealth. Using the 
Retirement History Survey, Levin found that housing wealth has essentially no effect on consumption. Out of eight spending categories, only three reported a statistically significant difference between the respective coefficients for liquid and housing wealth. This finding contradicts the studies using aggregate data summarized above. A possible reason could be the fact that every interviewee in the survey is at least 65 years old. If elderly people tend to view housing wealth more as consumption than as an investment item, their housing wealth effect will be lower than would otherwise be the case. Using the CEX and SCF, Bostic, Gabriel, and Painter (2009) find that, while incorporating all households in their sample, there is no evidence for an important housing wealth effect. Among home owners, however, the housing wealth elasticity is found to be consistently significant and larger than the stock wealth elasticity. Their paper also suggests different consumption behaviors for creditconstrained versus non credit-constrained samples. Using household-level data in the U.K., Campbell and Cocco (2007) found the response of household consumption to housing prices is rather large and significant. They also provide evidence for the heterogeneity of this response. More specifically, the estimated housing price elasticity is as large as 1.7 for old home-owners but near zero for young renters. Attanasio, Blow, Hamilton, and Leicester (2009), however, found a larger relationship between consumption and house prices for younger households. The authors then suggested that both consumption and house prices are responding to some common factors. Using a different British household-level dataset, Disney, Gathergood, and Henley (2010) found a small housing wealth effect of 0.01 after controlling for financial expectations, without which the estimated housing wealth effect would be significantly biased up. If simultaneity of this kind can be found even in micro data, where it should be harder to find, it appears to justify the concern with simultaneity problems using aggregate data.

The best known paper using geographical data is Case, Quigley, and Shiller (2005). Using quarterly U.S. state-level data for 1982 through 1999, the authors found a significant housing wealth elasticity of about 5 percent, but an economically negligible stock wealth elasticity under most model specifications. When using a panel of annual data for 14 developed countries, they found an even larger housing wealth elasticity, in the range of $11-15$ percent. Nonetheless, under all cases, they found no evidence for an important stock wealth effect. Case, Quigley, and Shiller (2011) extended their state-level data up to 2009 and applied the same technique to address the wealth effect question. Similar to their previous study, the authors found significant and rather large housing wealth effect on consumption and consistently found larger housing wealth effect than stock wealth effect. However, after including data during $2005-2009$, the recent housing market meltdown, the authors found that increases and declines in the housing market have equally important effects on consumer spending, which contradicts their previous findings. Bayoumi and Edison (2003) used data for 16 industrial countries and found significant wealth effects for most 
samples and periods. Their estimated housing wealth effect was consistently larger than their estimated equity wealth effect. Ludwig and Sløk (2002) found evidence contrary to the studies cited above. Using annual data from 16 OECD countries, and taking housing prices and stock market prices as proxies for their respective wealth components, the authors reported an estimated stock wealth elasticity twice the estimated housing wealth elasticity. Additionally, both estimates were found to be positive and statistically significant. On the other hand, Girouard and Blöndal (2001) also used OECD data, but were unable to arrive at consistent results when comparing housing wealth with financial wealth. Dvornak and Kohler (2003), using Australian state-level data, found a larger stock wealth effect than housing wealth effect.

\section{Limitations of existing state-level consumption and stock wealth data}

Case, Quigley, and Shiller (2005) relate state-level quarterly spending growth to measures of quarterly state-level stock wealth and housing wealth for the U.S. for the period 1982 through 1999, and Case, Quigley, and Shiller (2011) extend that

estimation to 2009. But serious problems afflict their measures of both financial wealth and consumption.

\subsection{Financial Wealth}

No direct measures of state-level financial wealth data exist, so CQS had to construct their own estimates. The best data they were able to find was occasional information about state-level holdings of mutual funds. In order to produce a measure of statelevel stock wealth, CQS assumed that the ratio of mutual funds holdings to holdings of other financial assets was identical across states (and equal to the aggregate value of that ratio), which implies that the distribution of financial wealth across states can be constructed using the pattern of mutual fund holdings (for years in which mutual fund holdings are available). CQS obtained the mutual fund data for the years 1986, 1987, 1989, 1991, 1993, 2008, and 2009. In the absence of data for other years, they assumed a constant distribution of mutual fund holdings across states for the period 1982 - 1986 and 1993 - 1999. During those years, then, movements in the stock wealth of each state is assumed to mimic the movement of aggregate stock wealth. From 1999 to 2008, they assume that the ratio of mutual fund assets to total assets increases linearly so that it matches the aggregate figure in 1999 and 2008. (2008-2009 is the only pair of adjacent years in which the relevant data are available in both years to construct their measure without interpolation). 
One aspect of their methodology, at least, is subject to test: Their assumptions about the movements in the ratio of mutual fund holdings to total financial wealth. Figure 2 plots mutual fund holdings from FFA over the same period, and shows strong deviations from a linear increase in the ratio of mutual fund holdings to total financial assets at the aggregate level. Since aggregate data is the sum of state data, the CQS method must be producing mismeasurements of the state-level financial wealth data even if their assumption is correct that the ratio of mutual fund to total financial assets is identical across states. In principle, mismeasurement of a regressor tends to bias its coefficient toward zero; so an unfriendly interpretation of the CQS finding that the 'financial wealth effect' is small might be that this is because their measure of financial wealth changes is noisy.

\subsection{Consumption}

To the best of our knowledge, there exist three distinct state-level sources of consumption data - those used by Asdrubali, Sorensen, and Yosha (1996); Case, Quigley, and Shiller (2005) and Case, Quigley, and Shiller (2011); and Garrett, Hernàndez-Murillo, and Owyang (2004). Of these, only CQS utilized the data to examine wealth effects. The consumption data used by Asdrubali, Sorensen, and Yosha (1996), and CQS used estimates of retail sales obtained from private sector sources. However, in both cases, the quality of these data derived from the private sources is questionable. First, the methodology used in the data construction is never explicitly revealed by either private source. Second, retail sales are presented for states that do not implement sales tax, which constitutes perhaps the single most important source for calculating state retail sales after the Census Bureau ceased reporting monthly retail sales by state, in 1997. Last but not least, both sources vaguely note that important statelevel variables like wage and employment data are incorporated into the estimation of retail sales. As a result, use of these data is likely to generate unreliable estimations of the relationship between consumption and any variable that is correlated with wages or employment. (For example, a finding that 'consumption growth is related to the predictable component of wage growth,' a classic test of the permanent income hypothesis, would obviously be spurious if the measure of consumption was generated by imputation from wage growth data; the vague descriptions of the private firms' data construction methods suggest that this is more than a hypothetical problem.)

Given these problems, we are skeptical of the empirical results of any study that uses data from these private sources. (For considerably more discussion of these sources and their doubtful properties, see Zhou (2010)).

More promising is the method of Garrett, Hernàndez-Murillo, and Owyang (2004), who computed quarterly retail sales by dividing sales tax revenue by the sales tax rate. In principle this could potentially yield a good measure of state retail sales, and this method therefore provides the basis of the measure of spending growth measure we use 
in this paper. One problem, however, is that the sales tax revenues are occasionally measured with serious errors; this results in observations with unreasonably large consumption variations and apparent outliers. We carefully examined these events and found that many of them could be explained, and many of those that could not be explained were nevertheless obviously errors. Thus, our dataset "cleans up" these outliers and thereby improves upon the data used in Garrett et. al. (2004).

\section{Data Description}

This paper uses a panel dataset for 44 U.S. states as well as Washington, D.C., at a semiannual frequency for the period 2001 through 2005. The newly constructed datasets are for stock wealth and consumption at the state level. Other important variables include after-tax labor income and housing wealth. All are expressed in real per capita terms. There is evidence that the new data are more comprehensive and accurate than other existing alternatives. Some important findings will be discussed in the rest of this section. More detailed discussions can be found in Zhou (2010).

\subsection{Stock wealth data}

We obtained anonymous account-level records on financial wealth holdings at the ZIP +4 Code level from a private company. At the end of each semiannual cycle, that company collects data from more than 85 leading financial institutions in its network. Reporting institutions include major banks, brokerage firms, insurance companies and mutual fund dealers. Aggregate stock wealth growth rates, as measured by both the Flow of Funds Accounts (FFA) and the new dataset between 2000h1 and 2005h2, are presented in Figure 3. Despite using completely different data sources, Figure 3 shows that the two series move similarly to one another, suggesting that the new data is representative of the nation as a whole.

Stock market wealth is defined as the sum of directly and indirectly held stocks and equity mutual funds ('indirectly' held assets are, e.g., IRA and Keogh accounts). Stock wealth growth is constructed using a consistent method for all 50 states plus the District of Columbia. ${ }^{2}$ The geographic distribution of stock wealth growth is plotted in Figure 4. We find similar patterns across states, something to be expected given the fact that the U.S. stock market is so well integrated. Since there exists no alternative state-level wealth data for comparisons, we use stylized facts about the U.S. to understand if the state heterogeneity manifested in the figure reflects reality.

Florida and Arizona are the two states that have the highest percentage of retired people. As reflected in Figure 4, their seasonal patterns also distinguish them from other states. In order to better illustrate the differences, Figure 5 compares the stock

\footnotetext{
${ }^{2}$ Details on its construction can be found in the Appendix.
} 
wealth growth of Florida and Arizona with the average stock wealth growth of the other states. It indicates that Florida and Arizona have a much higher stock wealth growth rate than the other states during the second half of each year, and a much lower stock wealth growth rate during the first half of each year. This phenomenon might seem strange at first glance, but is actually an outcome of the "snow-bird effect." In the U.S., many retired people tend to move to Florida and Arizona during the winter and then move back to their permanent residences once the winter is over. If some such individuals update their physical mailing addresses with their financial institutions when they relocate, they effectively bring their assets along with them. ${ }^{3}$ Figures 5 therefore provide evidence that the data are indeed capable of capturing state-level variations that are both meaningful and independent of aggregate movements. (The patterns here also motivate our use of year-over-year growth averages in our empirical work, to avoid seasonal patterns of the kind identified here).

We exerted substantial effort to find any other measure of state-level financial resources with which the new data could be compared, without great success. The most plausible indicator is from Bloomberg, which reports local stock indices for 23 states; the literature on the "home bias" of investments would lead us to expect that the growth of this variable to be positively but not perfectly correlated with local stock wealth growth. Figure 6 presents the correlation between the local stock index and local stock wealth, broken down graphically. Out of the 23 calculated correlations, we find only 2 negative numbers. At the state-specific growth level, defined as state growth minus the U.S. national component, there are still 15 positive correlations. These facts further provide supporting evidence that the data is correlated with the true distribution of stock market wealth across states.

\subsection{Consumption data}

Since measures of personal consumption expenditure (PCE) at the state level are not available in the U.S., retail sales are used as a proxy for consumption. In the U.S., national retail sales account for roughly half of PCE, and The Retail Trade Survey is probably the single most important source for the national PCE estimation carried out by the Bureau of Economic Analysis (BEA). Actually, for nonbenchmarkyear estimates for most categories of PCE, the retail sales series are used in the interpolation and extrapolation process, as well as the "control total" calculation for each retail control group. ${ }^{4}$ These considerations provide us with a rationale for using retail sales in place of consumption.

However, retail sales data are not directly available in the U.S. at the state level. Following Garrett, Hernàndez-Murillo, and Owyang (2004), quarterly state-level gen-

\footnotetext{
${ }^{3}$ Per the practice of the private company that collects data from these financial institutions, the assets are now considered as belonging to the Zip Code +4 of the address to which the account statement is mailed.

${ }^{4}$ See Wilcox (1992) and http://www.bea.gov/methodologies/index.htm.
} 
eral sales tax revenues can be obtained from the Quarterly Summary of State and Local Government Tax Revenue, published by the U.S. Census Bureau. Together with general sales tax rates collected from various sources, ${ }^{5}$ state-level retail sales are computed by dividing the state general sales tax revenue by the general sales tax rate. One limitation of this method is that since 5 states do not have retail sales taxes, it can be applied only to 45 states and the District of Columbia. Nevada, however, is dropped in this study because of its discontinued data report and obvious poor data quality.

Strictly speaking, the computed retail sales are only one component of true retail sales, as they exclude items that are either not subject to sales tax or are part of special tax programs, i.e., liquor and cigarettes. Furthermore, there is unquestionably serious measurement error in the computed retail sales from a host of sources (including, for example, imperfect measurement of changes in retail sales tax rates and the distribution of tax rates across categories of goods). However, we discovered that 12 states actually directly report (taxable) retail sales for the same period during which state-level stock wealth data is available. ${ }^{6}$ These measures are more comprehensive than our computed measure of retail sales, as they either include all consumption items (such as when government-reported gross retail sales are used) or at least include

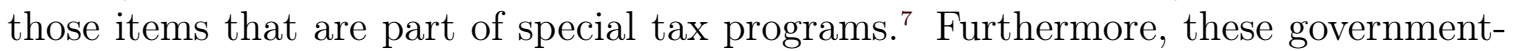
reported measures should be more accurate and reliable than the computed ones, since local governments have access to more information regarding their own sales tax system and tax collection practices than other people do. ${ }^{8,9}$

Ideally, government-reported (taxable) retail sales should be used as a measure of consumption. However, since they are only available for a limited number of states, this paper compiles three sets of consumption data according to the quality of the retail sales data. The first one includes those 12 states that have government-reported retail sales or taxable retail sales; it is categorized as "Best Data." The second set is called "Good Data," which is the computed retail sales with outliers taken care of. The third set is called "Combined Data," and is "Best Data" combined with "Good Data" whenever the former is not available. Table 1 presents the summary statistics

\footnotetext{
${ }^{5}$ The state general sales tax rate can be found from various sources such as the State Government Tax Collections, and the Tax Foundation's Facts and Figures on Government Finances.

${ }^{6}$ Data are obtained from the websites of the respective state tax administrations.

${ }^{7}$ Special tax programs notably constitute roughly 25 percent of total sales tax revenue.

${ }^{8}$ They are either calculated by local governments (as in Virginia), or are derived directly from the reports on dealers' returns (as in Iowa).

${ }^{9}$ Some other retail sales measures are also available from various private sources, among which the one published by Sales \& Marketing Management is probably the most utilized dataset in the recent literature. These measures, nevertheless, share some common issues: the construction is not transparent and usually involves assumed models which can undermine our analysis. Denoting the retails sales measured by Sales \& Marketing Management $C$ SMM the retail sales computed following Garrett, Hernàndez-Murillo, and Owyang (2004) $C^{\mathrm{GHO}}$, and the former combined with retail sales measures published by local government $C^{\text {ZHOU }}$, Table 2 compares these three different measures with a benchmark denoted by $C^{\mathrm{HS}}$, which was published by the Census Bureau but only existed for a limited time of period and 19 large states. Figure 7 and 8 compare them at the aggregate and state (Virginia) level respectively.
} 
of each set of consumption data. Please refer to the third chapter of Zhou (2010) for a more detailed discussion of the consumption data.

\subsection{Data from other sources}

Other important variables used in this paper include quarterly after-tax labor income and housing wealth. After-tax labor income is calculated following Lettau and Ludvigson (2001). The formula used to construct state-level housing wealth is similar to the one adopted by CQS, and is given as follows:

$$
w_{i, t}^{h}=\left(H O_{i, t} * H H_{i, t}\right) * H P I_{i, t} * H V_{i},
$$

where $w_{i}^{h}$ is the value of the owner occupied housing wealth for state $i$; $H O$ is the home ownership rate, taken from the Census Bureau; HPI is the weighted repeat sales housing price index, taken from the Federal Housing Finance Agency (FHFA); and $H V$ is the average home price for 1999, taken from the 2000 Census. Summary statistics of all newly constructed data series are presented in Table 1.

\subsection{Data issues}

One important data issue arises here. As mentioned above, all variables except the stock market wealth are available at quarterly frequencies. To make them analogous to the stock market wealth, this paper takes their means over the quarters for each half-year, thus converting them into semiannual frequencies.

The dataset, however, features evident and sizable seasonal patterns at the semiannual frequency, especially for the constructed consumption data. We made a considerable effort at removing these seasonal patterns in a consistent fashion, but were unable to do so at the semiannual frequency. This is largely because of the heterogeneity of seasonal patterns across states and the relatively short time horizon. (Many state governments recommend using longer time spans for more reliable trends.) It should be recognized that measures of taxable sales (or revenue) at higher frequencies could be unrepresentative for the purpose of comparison. This is because of timing errors over the year-long period. The above consideration persuaded us to use annual growth rates so as to eliminate seasonal effects, at the cost of fewer observations and thus a reduced regression power.

Additionally, to avoid a time aggregation problem, annual averages are not used to calculate growth rates. Instead, $\Delta c_{i, t}$ is computed as the log difference between consumption for the first half of year $t$ and for year $t-1$. The first half was chosen in consideration of the fact that the state fiscal year ends on June 30th. It is arguable that data collected towards the end of a fiscal year is more accurate than data collected at any other time of year. 


\subsection{Another look at the new data}

Since this paper relies heavily on the two newly constructed datasets, before examining wealth effects, we report a simple regression of the form

$$
\Delta c_{i, t}=\alpha_{t}+\beta_{1} \Delta y_{i, t}+\beta_{2} \Delta w_{i, t}^{f}+\beta_{3} \Delta w_{i, t}^{h}+\varepsilon_{i, t},
$$

where $\Delta$ denotes the growth rate of a variable, i.e., the log difference of the variable in real per capita terms. Equation 1 is a simple description of the data without taking into consideration simultaneity and aggregation problems. Table 3 reports the results for all three datasets. It shows that income growth is the one variable that consistently has the largest and most significant coefficient. Perhaps the most interesting finding is that there is evidence that consumption positively correlates with the growth rates of both housing wealth and stock wealth when they are regressed separately. Conversely, whenever income growth is included, their respective coefficients become much less significant, in connection with the reduced sizes. The data archive that can produce all results in this study is available from http: //econ.jhu. edu/people/ccarroll/papers/zcWandCdynByState. zip. ${ }^{10}$

\section{Regressions}

\subsection{Wealth effect estimation}

Many studies in the current literature, particularly those that focus on the immediate response of consumption to wealth, adopt regressions similar to those used in Equation 1. ${ }^{11}$ However, even if simultaneity problems did not exist, such regressions would not yield straightforward measures of wealth effects, since they only report the contemporaneous growth correlation between consumption and wealth. Worse, in this specification it is not straightforward to test the interesting hypothesis that stock and housing wealth effects are of equal size (which is assumed whenever an overall "wealth effect" is estimated, but may not be true). ${ }^{12}$ In order to solve this problem, this paper adopts an approach similar to that employed by Carroll, Otsuka, and Slacalek (2011); those authors use the ratio of the change in each variable relative to an initial level of consumption spending. Here, we use average aggregate labor income between 1996

\footnotetext{
${ }^{10}$ Instructions on how to obtain the data on the growth rate of financial wealth for U.S. states can be found in the ReadMe.txt file for the data archive.

${ }^{11}$ Cointegration analysis is another standard method used in the current literature to study long-term MPCs. Nevertheless, given the relatively short time horizon, the data used in this paper does not allow for such an analysis. Additionally, cointegration analysis is intrinsically problematic. The most relevant problem with respect to income and wealth effect analysis is the requirement that the cointegrating vectors remain stable, which in turn requires a stable saving rate. This requirement, however, obviously runs contrary to what the data tells us, as illustrated in Figure 1.

${ }^{12}$ One benefit of such estimations is that they produce certain results comparable to those in the current literature. For the sake of comparison, the results of similar estimations are included in the appendix of this paper.
} 
and 2000 as the denominator instead. Specifically, if we define

$$
\begin{aligned}
\Delta \tilde{c}_{i, t} & =\frac{C_{i, t}-C_{i, t-1}}{\bar{Y}} \\
\Delta \tilde{y}_{i, t} & =\frac{Y_{i, t}-Y_{i, t-1}}{\bar{Y}} \\
\Delta \tilde{w}_{i, t}^{h} & =\frac{W_{i, t}^{h}-W_{i, t-1}^{h}}{\bar{Y}} \\
\Delta \tilde{w}_{i, t}^{f} & =\frac{\left(W_{i, t}^{f}-W_{i, t-1}^{f}\right)}{\bar{Y}},
\end{aligned}
$$

where $Y_{i, 0}$ is the state after-tax labor income at 2000h1, then the following regression

$$
\Delta \tilde{c}_{i, t}=\alpha_{t}+\beta_{1} \Delta \tilde{y}_{i, t}+\beta_{2} \Delta \tilde{w}_{i, t}^{f}+\beta_{3} \Delta \tilde{w}_{i, t}^{h}+\Delta \tilde{\varepsilon}_{t},
$$

would (in the absence of simultaneity problems) produce direct measures of the MPC out of the changes in housing wealth and stock wealth.

As with Equation 1, Equation 2 is subject to serious endogeneity problems, and thus must be considered as simply another description of the data. Table 4 indicates that under this model specification, income change is still the most correlated variable with respect to consumption.

In order to address the endogeneity and simultaneity problems that Equation 2 is subject to, we briefly revisit classic consumption theory. The relationship between consumption and wealth and income can be described by the Life-Cycle/Permanent Income Hypothesis. Specifically, a consumer wants to

$$
\max \mathbb{E}_{t}\left[\sum_{s=t}^{\infty} \beta^{s-t} \mathrm{u}\left(c_{s}\right)\right]
$$

subject to the budget constraint, where $\beta$ is the time preference, and $u\left(c_{t}\right)$ is the utility function. If the utility function takes a quadratic form as assumed in Hall (1978), it can be easily shown that, under certain conditions, consumption will follow a random walk, i.e.,

$$
\begin{aligned}
\Delta c_{t+1} & =\epsilon_{t+1}, \\
\mathbb{E}_{t}\left[\epsilon_{t+n}\right] & =0 \forall n>0 .
\end{aligned}
$$

Thus, the theory implies that consumption responds to unexpected shocks only. In other words, information known to consumers at the time when consumption choices are made cannot have any predictive power for consumption changes in any future periods.

The random walk proposition, therefore, can help us address the endogeneity and simultaneity problem, as it suggests that current consumption growth would not be correlated with any lagged wealth growth. Nevertheless, time aggregation and measurement error could cause current consumption changes to correlate with once lagged income and wealth changes, even if the PIH holds true. Aggregation also matters when the PIH holds in continuous time, and the measures of consumption are 
based on time averages. Under this situation, changes in time-averaged consumption will have nonzero first order serial correlations; this will lead to nonzero correlations between changes in consumption and once-lagged variables. It is also easy to prove that measurement errors in the consumption level could cause measured consumption changes that correlate with once-lagged explanatory variables. ${ }^{13}$ Given the above considerations, the following equation is employed to see if we can detect delayed effects of wealth changes: ${ }^{14}$

$$
\Delta \tilde{c}_{i, t}=\alpha_{t}+\beta_{1} \Delta \tilde{y}_{i, t-2}+\beta_{2} \Delta \tilde{w}_{i, t-2}^{f}+\beta_{3} \Delta \tilde{w}_{i, t-2}^{h}+\Delta \tilde{\varepsilon}_{t} .
$$

Equation 3 employs twice-lagged independent variables, and thus gives a rudimentary estimate of current MPCs out of changes in housing wealth and stock wealth that occurred two periods prior, which would be zero in the random walk model.

There are, however, two minor modifications that need to be made. First, what $C_{i, t}$ captures here is not the real personal consumption for state $i$, but the state's taxable retail sales. Thus, using $C_{i, t}$, the estimation of Equation 3 actually yields the effect of changes in wealth on taxable retail sales. To gauge the approximate change in real consumption, it is assumed that initial state consumption can be determined by $C_{i, 0}^{*}=Y_{i, 0} * \frac{C_{0}^{*}}{Y_{0}}$, where $C_{0}^{*}$ and $Y_{0}$ are aggregate personal consumption expenditure and after-tax labor income, respectively. In addition, we assume that the ratio of retail sales to real consumption holds constant over time, i.e., $\frac{C_{i, t}}{C_{i, t}^{*}}=\frac{C_{i, 0}}{C_{i, 0}^{*}}$. Therefore, changes in state consumption can be measured roughly by

$$
\begin{aligned}
\left(C_{i, t}^{*}-C_{i, t-1}^{*}\right) & =\left(C_{i, t}-C_{i, t-1}\right) *\left(\frac{C_{i, 0}^{*}}{C_{i, 0}}\right) \\
& =\left(C_{i, t}-C_{i, t-1}\right) *\left(\frac{C_{0}^{*}}{Y_{0}} \frac{Y_{i, 0}}{C_{i, 0}}\right) .
\end{aligned}
$$

The same problem arises when measuring stock wealth. Thus, it is assumed for all states and time periods that $\frac{W_{i, t}^{f}}{W_{i, t}^{f *}}=\frac{\sum_{i} W_{i, 0}^{f}}{W_{F F A, 0}^{f}}$, where $W_{i, t}^{f *}$ denotes the real state stock wealth at time $t$.

Therefore, if we redefine

$$
\begin{aligned}
\Delta \tilde{c}_{i, t} & =\frac{C_{i, t}-C_{i, t-1}}{\bar{Y}} *\left(\frac{C_{0}^{*}}{Y_{0}} \frac{Y_{i, 0}}{C_{i, 0}}\right) \\
\Delta \tilde{w}_{i, t}^{f} & =\frac{\left(W_{i, t}^{f}-W_{i, t-1}^{f}\right)}{\bar{Y}} * \frac{W_{F F A, 0}^{f}}{\sum_{i} W_{i, 0}^{f}},
\end{aligned}
$$

the regression of Equation 3 ends up reporting approximate estimates of the MPC out of changes in housing wealth and stock wealth.

\footnotetext{
${ }^{13}$ Let us assume that $c_{t}=c_{t-1}+\varepsilon_{t}$ and $c_{t}=c_{t}^{*}+v_{t}$, where $c_{t}$ is real consumption, $c_{t}^{*}$ is the measured consumption, and $v_{t}$ is the measurement error. Although real consumption growth follows a random walk, the measured consumption growth, $\Delta c_{t}^{*}=\varepsilon_{t}-\left(v_{t}-v_{t-1}\right)$, is correlated with the once-lagged information.

${ }^{14} \mathrm{IV}$ regression is another commonly used method to solve endogeneity problems. However, variables lagged by two years have weak explanatory power, especially for income and stock wealth growth. Thus, it would lead us to another econometric issue - weak instruments.
} 
Table 5 summarizes the results of our estimations using Equation 3. It indicates that all three datasets report similar results, with the exception that none of the estimations from "Best Data" is statistically significant. Given the small sample size of the "Best Data" sample, this is perhaps not too surprising.

Table 5 shows that the coefficients of income changes are all positive and large. It therefore implies that income changes have a fairly big impact on consumption, despite the two-year lag. This, however, contradicts the random walk theory as predicted by the Permanent Income Hypothesis.

The wealth effect from lagged changes in financial wealth, on the other hand, is found to be both statistically insignificant and economically negligible. This finding is consistent with Dynan and Maki (2001), who found that the impact of stock wealth on consumption very quickly becomes apparent, and any lagged change in stock wealth beyond 9 months does not have any significant effect on consumption.

However, we observe highly significant and large coefficients for housing wealth in two out of the three datasets. Additionally, all three datasets indicate an MPC out of housing wealth changes that occurred two years prior around the neighborhood of 5 cents.

There are several reasons why the response to housing wealth shocks may be slower than the response to financial wealth shocks. Unlike stock prices that can be easily tracked daily online or in newspapers, house prices might be difficult to observe accurately or regularly. Homeowners might be less aware of short-run changes in house prices and it might take a homeowner a while to realize that his/her house price has changed. Additionally, the cost of realizing capital gains on housing wealth is lumpy. As a result, the response to housing wealth growth is not likely to be entirely contemporaneous.

What is more interesting is that the difference between the housing wealth effect and the stock wealth effect is found to be statistically significant for "Good Data," and on the verge of being significant for "Combined Data."

\subsection{A habit formation test}

A method for formalizing the sluggishness of the response of consumption to changes in wealth was proposed by Carroll, Otsuka, and Slacalek (2011) (henceforth 'COS'), who show how to derive "eventual" wealth effects implied by serial correlation in consumption growth. The basic idea is, if there is evidence of habit formation, consumption growth will be serially correlated. Thus, any impact that wealth changes have on consumption could be delivered through the serial correlation of consumption growth. The eventual wealth effect then can be derived by dividing the short run wealth effect by one minus the habit formation coefficient. We attempt to test this 
method of describing the consumption process using the equation derived by COS:

$$
\Delta \tilde{c}_{i, t}=\alpha_{t}+\lambda E_{t-2} \Delta \tilde{c}_{i, t-1} .
$$

where the coefficient $\lambda$ is expected to indicate the strength of habit formation.

Table 6 reports the estimations using Equation 6. Using currently available statelevel instruments, the results provide no evidence of habit formation. ${ }^{15}$ This could be because of the short time horizon of the data, and the corresponding weakness of IV techniques like the one employed for this test.

\subsection{Post 2005}

The U.S. economy entered a serious downturn in 2007 and is currently going through a weak recovery. Therefore, it would be illuminating if we can conduct a wealth-effect analysis using state-level data post 2005. State-level financial wealth data, however, is currently only available through 2005. As a result, our analysis in this section is performed without financial wealth growth. This is arguably valid since financial wealth growth was found insignificant in previous sections.

Similar to Table 3 and 4, Table 7 and 8 describe the data between 2001 and 2009, and present the test of structural break after 2005. It shows that both income and housing wealth growth are positively and significantly correlated with concurrent consumption growth. The null hypothesis of equal correlation between consumption and income and/or housing wealth before and after 2005, however, is rejected under most scenarios. More interestingly, new data tends to present a higher correlation between consumption and income/housing wealth after 2005. Liquidity constraints might be a possible reason that income and wealth are more correlated with consumption during a recession.

Employing Equation 3, Table 9 repeats the wealth effect analysis without financial wealth growth. Neither income nor housing wealth effect is found to be significant. Furthermore, all three datasets show a negative coefficient for housing wealth growth, indicating that consumption will decline in reaction to increases in housing wealth two years ago. An obvious explanation is that the two-year lag is too long if there is a bubble that inflates and then bursts, and if there are immediate and once-lagged effects of housing wealth changes on consumption that are larger than the twice-lagged effects. Housing price bubbles and thus rapid increases in housing wealth occurred before the housing market breakdown is the exact reason why the economy took a sharp turn in 2007.

The rest of this section is inspired by the work of Mian and Sufi (2011), who study the patterns of household debt at the county level from 2002 to 2007, and investigate how they are correlated with the following economic recession and recovery. They find

\footnotetext{
${ }^{15}$ Many other IV sets were tested but also failed to demonstrate a positive and significant habit formation coefficient with reasonable first stage results.
} 
that not only did high household debt counties experience larger declines in prices during the recession, but they also recover more slowly after the recession. Employing their methodology, we take the 6 states that had the highest house price growth during 2001-2006, then show the subsequent behavior of house prices and consumption for 2007-2009. We do the same thing for the 6 states having the lowest housing wealth growth between 2001-2006.

Figure 9 compares consumption and housing wealth, both indexed to 2000h1, for the top and bottom 6 states during 2001-2006. The figure reflects the well-known fact that housing wealth growth was highly heterogeneous across states. The top 6 states experienced a sharp increase in housing wealth up to 2006 and experienced an equally sharp decline in housing wealth starting 2007. On the other hand, the bottom 6 states show a much smoother housing wealth growth path through the whole period. Figure 9 further shows that consumption of both high and low housing wealth growth states contracted in 2001-2003, likely due to the recession that started in 2001. Nevertheless, consumption of the top 6 states with high housing wealth growth was rapidly increasing as the real estate bubble was forming. In contrast, consumption of the bottom 6 states only grew slightly as the housing market was booming nationwide. By the time when national housing price peaked, consumption of the top 6 states has been about 10 percent higher than its level in 2000. But the bottom 6 states were still inching toward their 2000 level.

The observations above lead to an interesting question: Given what we knew from the 2001-2006 estimates, how well would we have been able to predict consumption declines after 2006 in the two groups of states had we known the housing wealth and income changes they would experience over 2007-2009? In other words, what fraction of the consumption declines after 2006 can be associated with the concurrent housing wealth and income changes? (We freely admit that this association cannot properly be interpreted as causal, for all the reasons articulated in the introduction).

To address this question, we start by regressing consumption growth, $\Delta c_{i, t}$, on a time dummy, income growth, and housing wealth growth, $\Delta w_{i, t}^{h}$, using data between 2001-2006. We then predict consumption growth for 2007-2009 by setting the intercept term to be zero. Figure 10 compares the actual and predicted consumption growth for the top and bottom 6 states. It shows that the top 6 states experienced an immediate drop in consumption as soon as the housing market turned south in 2007, and continued with a sharp decline in 2008 as the subprime crisis intensified. Table 10 further shows, however, that of the cumulative decline in consumption from 2006 to 2009, only about 19 percent can be 'explained' by the declines in income and housing wealth. On the other hand, Figure 10 shows that states with the bottom housing wealth growth hardly experienced any major consumption contraction until 2009, when the subprime crisis had spread to non-subprime areas and other industries. This nicely matches findings by Mian and Sufi (2010) who find that spending on motor vehicles in non-housing-boom states did not collapse until 2009, while motor 
vehicle purchases began declining considerably earlier in the states that had a housing bubble then bust. Together, these points suggest that, while problems in the housing market may have been an important trigger for the 2008-2009 crisis, the precipitous drop in consumption spending in that period went well beyond what would have been expected just from the loss of housing wealth and income.

\section{Conclusion}

This paper's main contribution is to construct and describe two panel datasets: One for financial wealth for U.S. states for 2000-2005, constructed from anonymous proprietary account-level records of geographic wealth holdings, and one for statelevel consumption data, constructed using data on retail sales tax revenues from the Census of State Governments (and, for some states, from state-level estimates of retail sales); and to argue that these datasets are substantially better than those that have been used by previous authors. We then combine these datasets to provide new estimates of the relationship between spending growth and current and lagged changes in stock wealth and housing wealth. Consistent evidence is found for large but sluggish housing wealth effects. Based on the results from our new approach, two out of the three datasets indicate that the MPC out of a one dollar change in two-year lagged housing wealth is about 5 cents. In addition, the twice-lagged income change is also found to be strongly related to the current consumption change. Both findings lead to the rejection of the random walk model of consumption. Furthermore, a statistically insignificant and economically small stock wealth effect is found for almost all specifications, although large standard errors mean that the differences of the financial wealth effect from housing wealth effects are statistically insignificant.

In addition, the paper finds evidence for a strong association between consumption and housing wealth declines in the period after the real estate bubble burst; the states with the biggest housing wealth decline experienced substantially larger declines in consumption spending. Our results also lend tentative further support to the proposition asserted in CQS, in Carroll, Otsuka, and Slacalek (2011), and elsewhere that movements in housing wealth and financial wealth have different effects, with housing wealth changes apparently exerting a large influence on household spending even two years after the impulse. In addition to their salience for explaining recent events, these results might also help explain the strength of consumption following the bursting of the stock market bubble at the end of the 1990s: at the same time the stock bubble was bursting, housing wealth had shown substantial gains, and with a larger and more sluggish MPC might have been sufficient to explain the strength of household spending in that era (in addition to its weakness recently); see Figure 11 in the appendix for a breakdown of the movements in wealth between financial and nonfinancial that supports this story. 


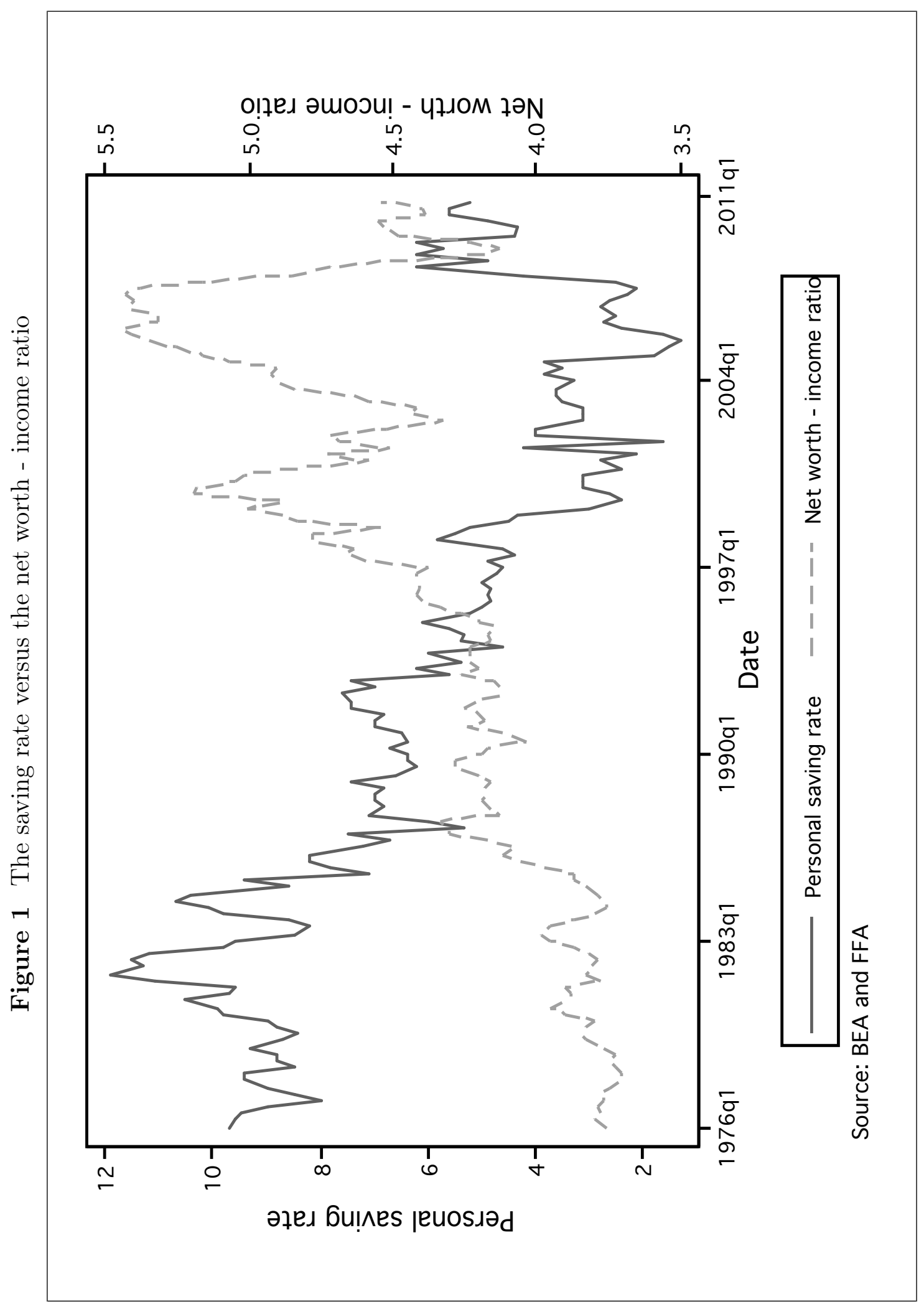




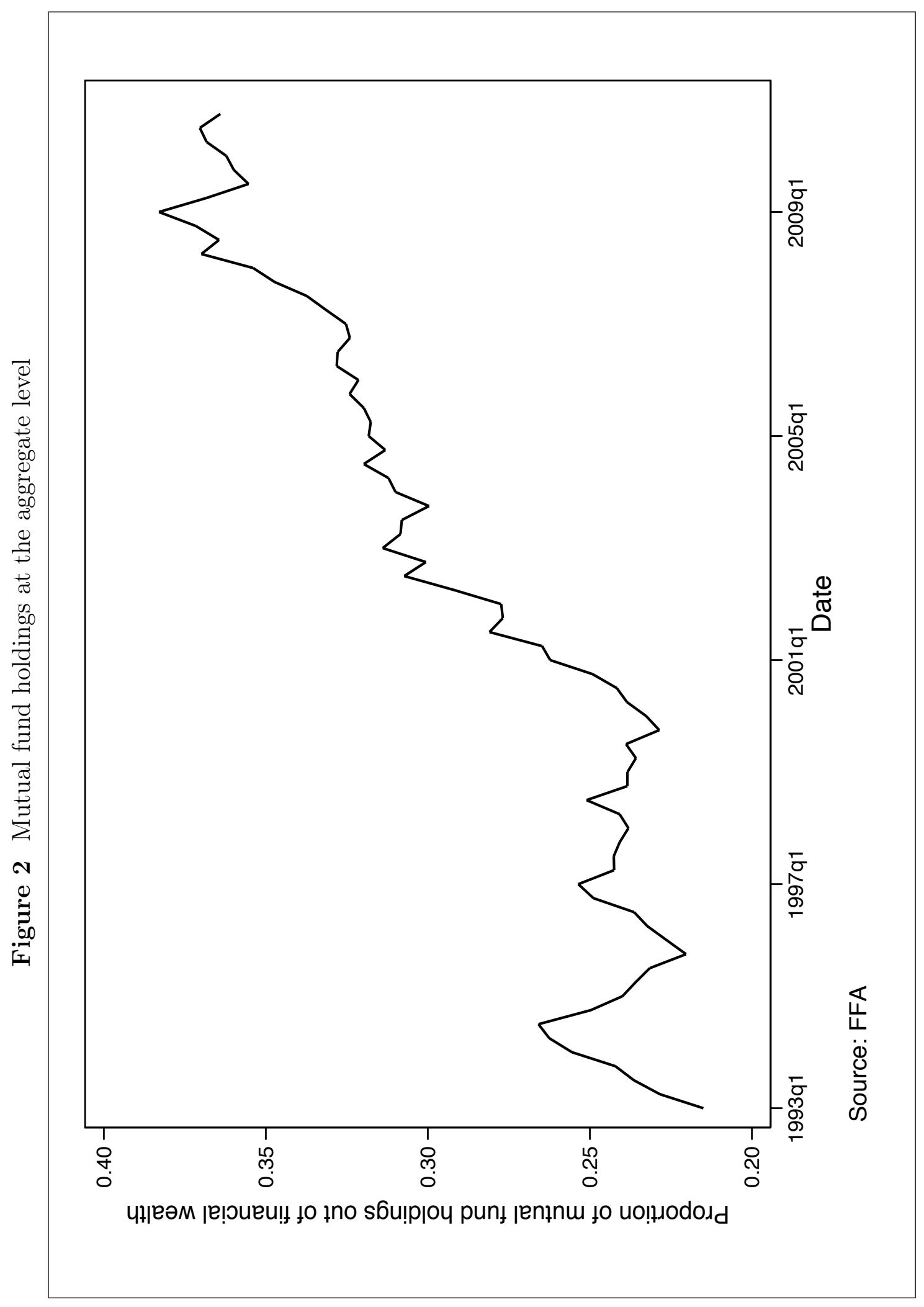




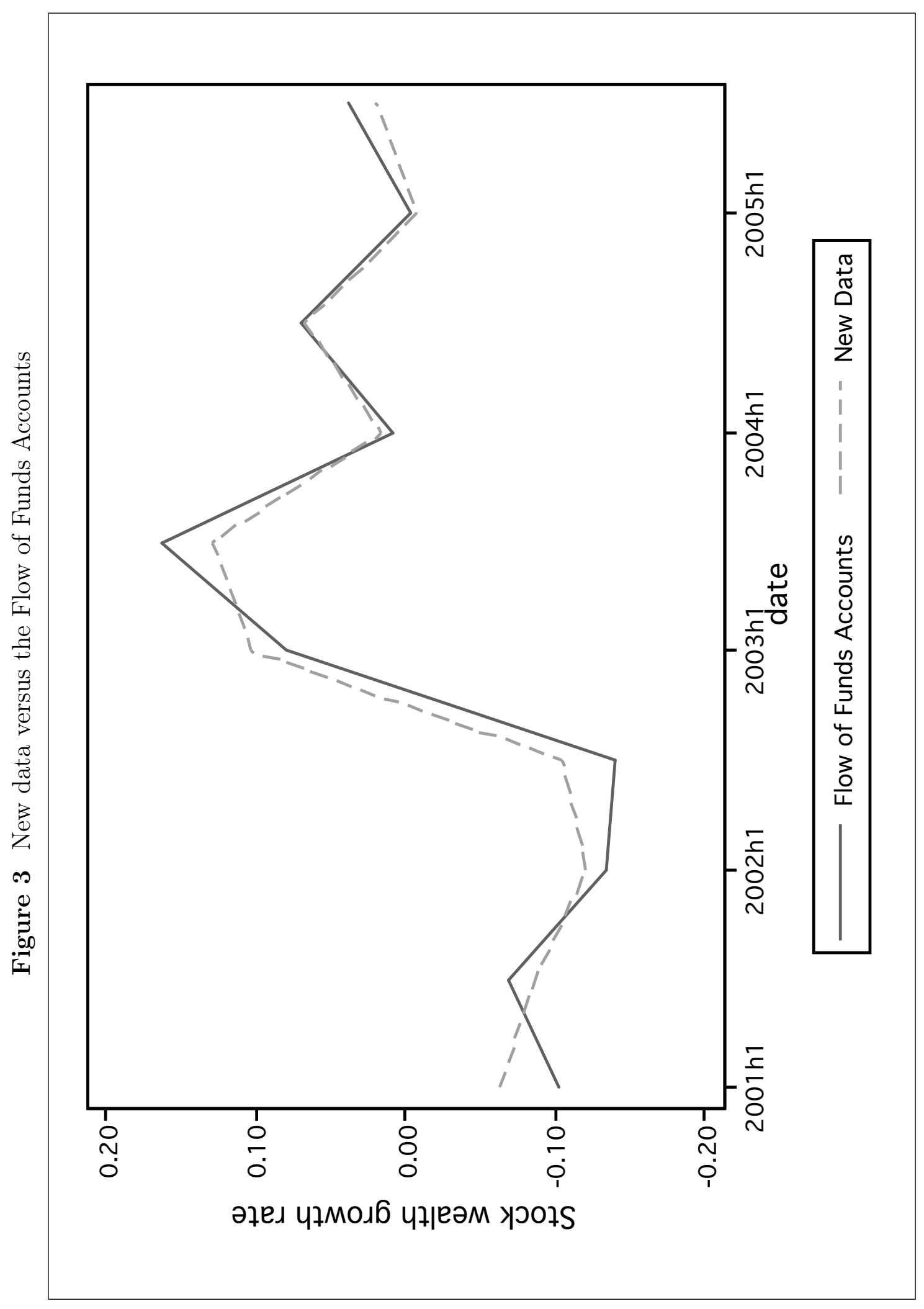




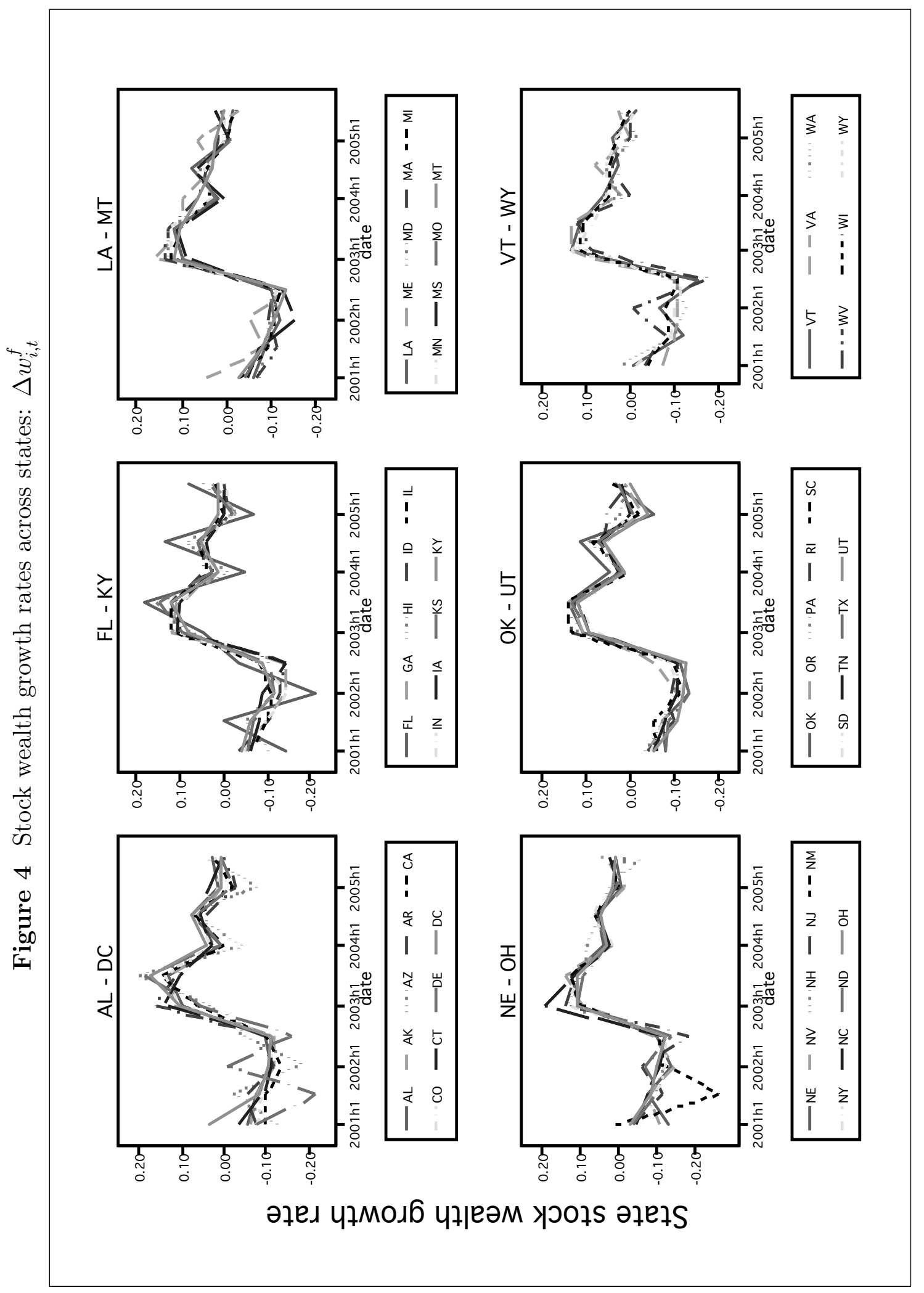




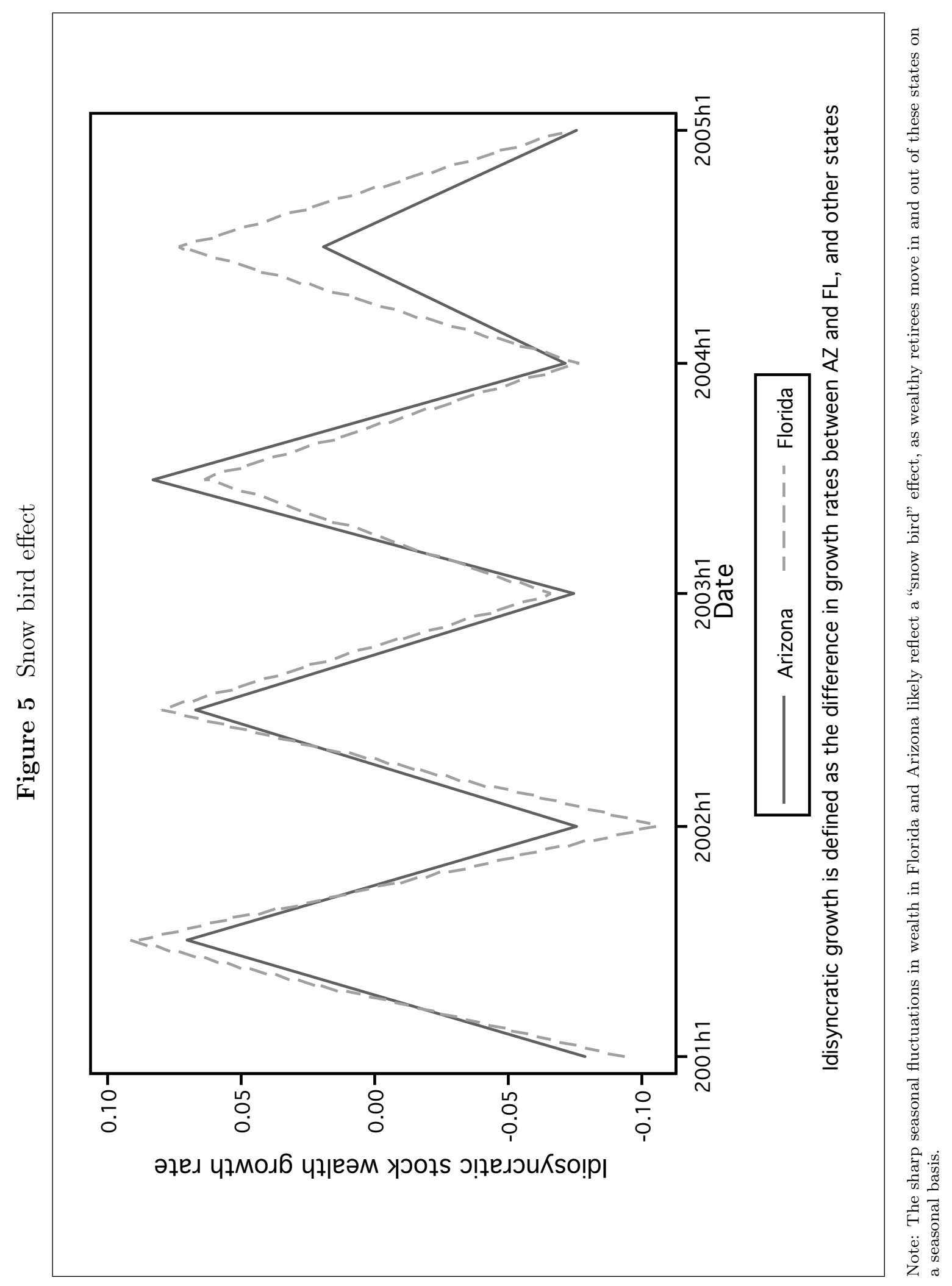


Figure 6 The local stock index versus state stock wealth

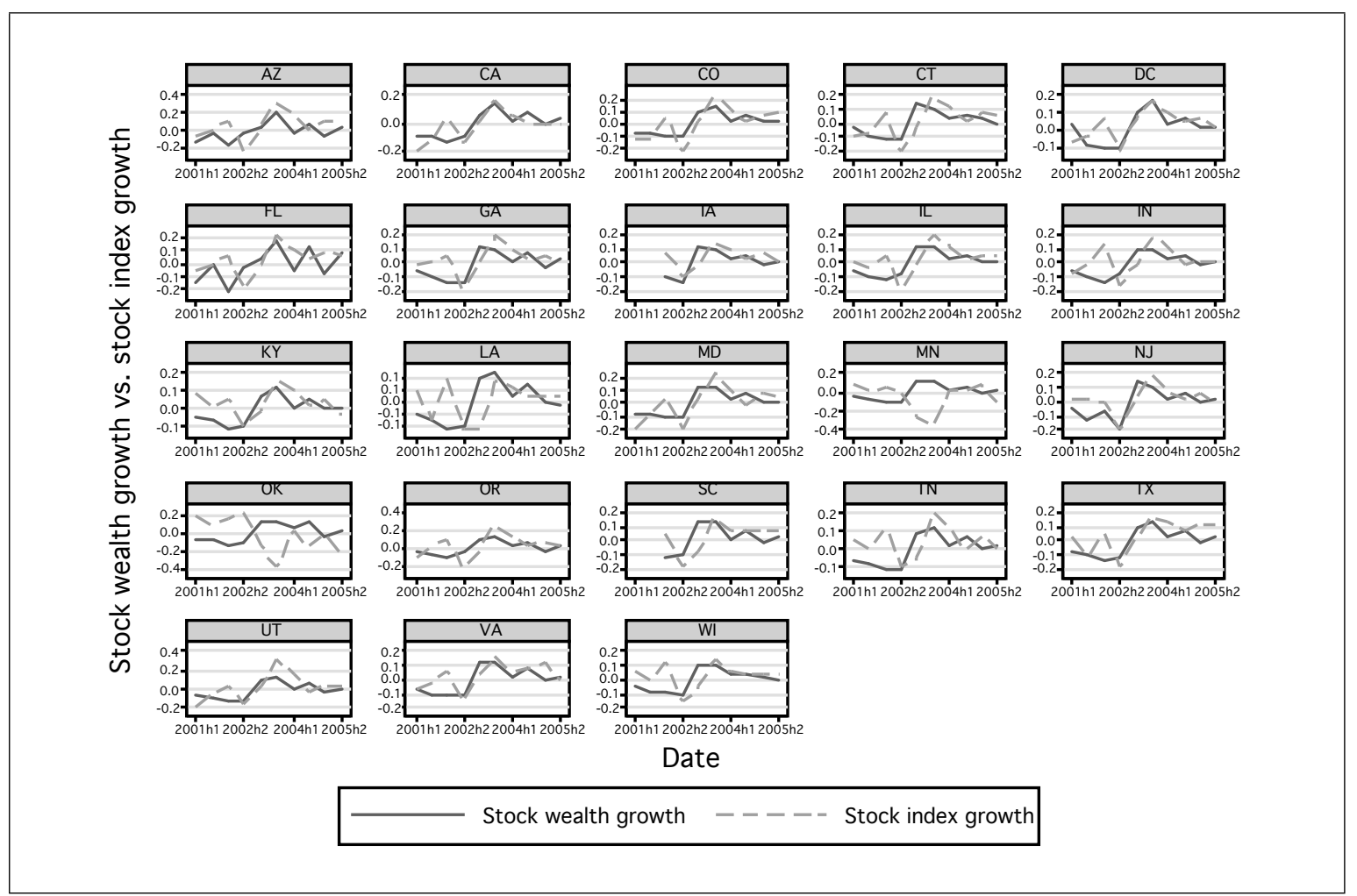

(a) State stock wealth growth versus local stock index growth

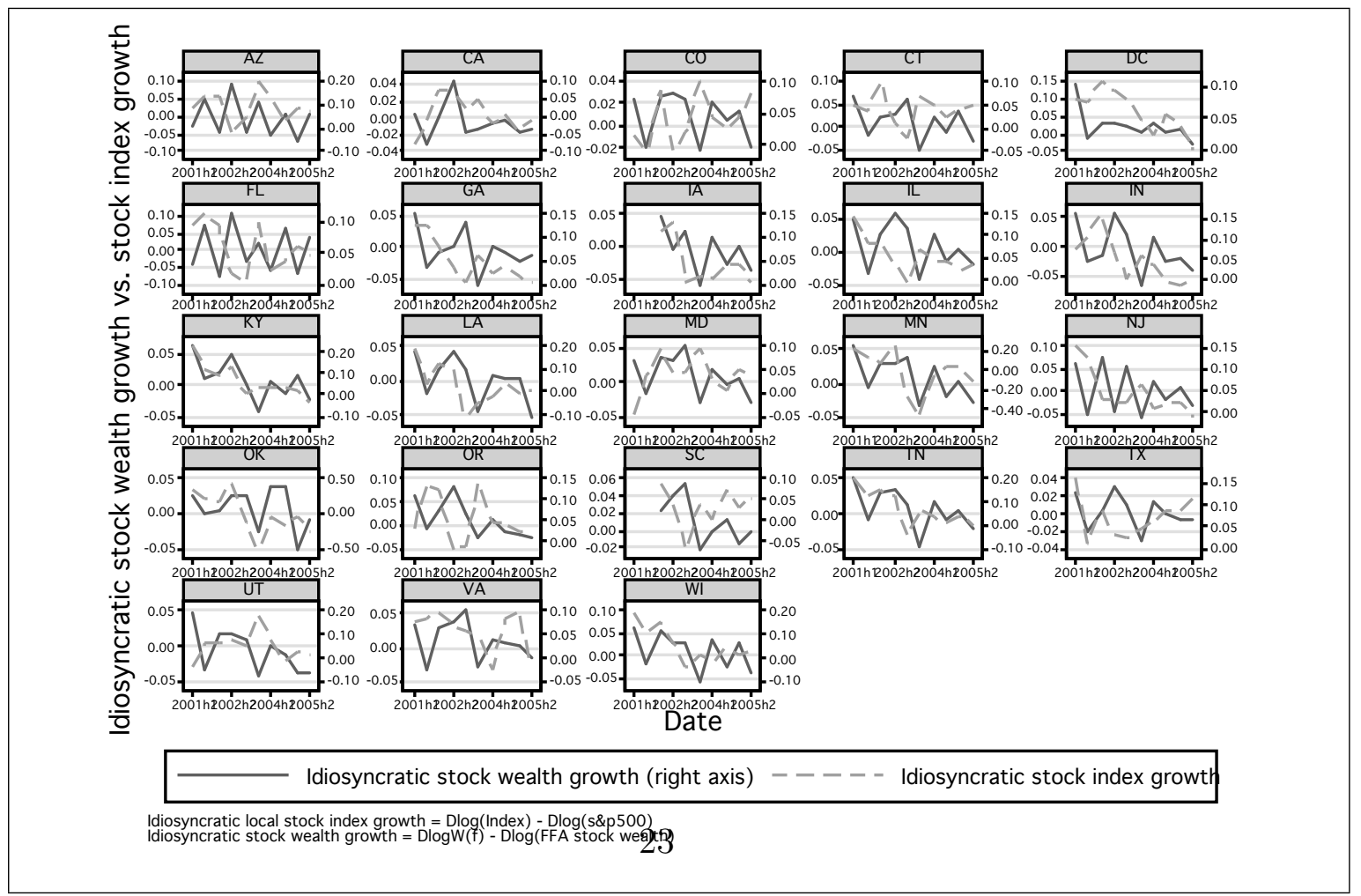

(b) Idiosyncratic state stock wealth growth versus idiosyncratic local stock index growth 


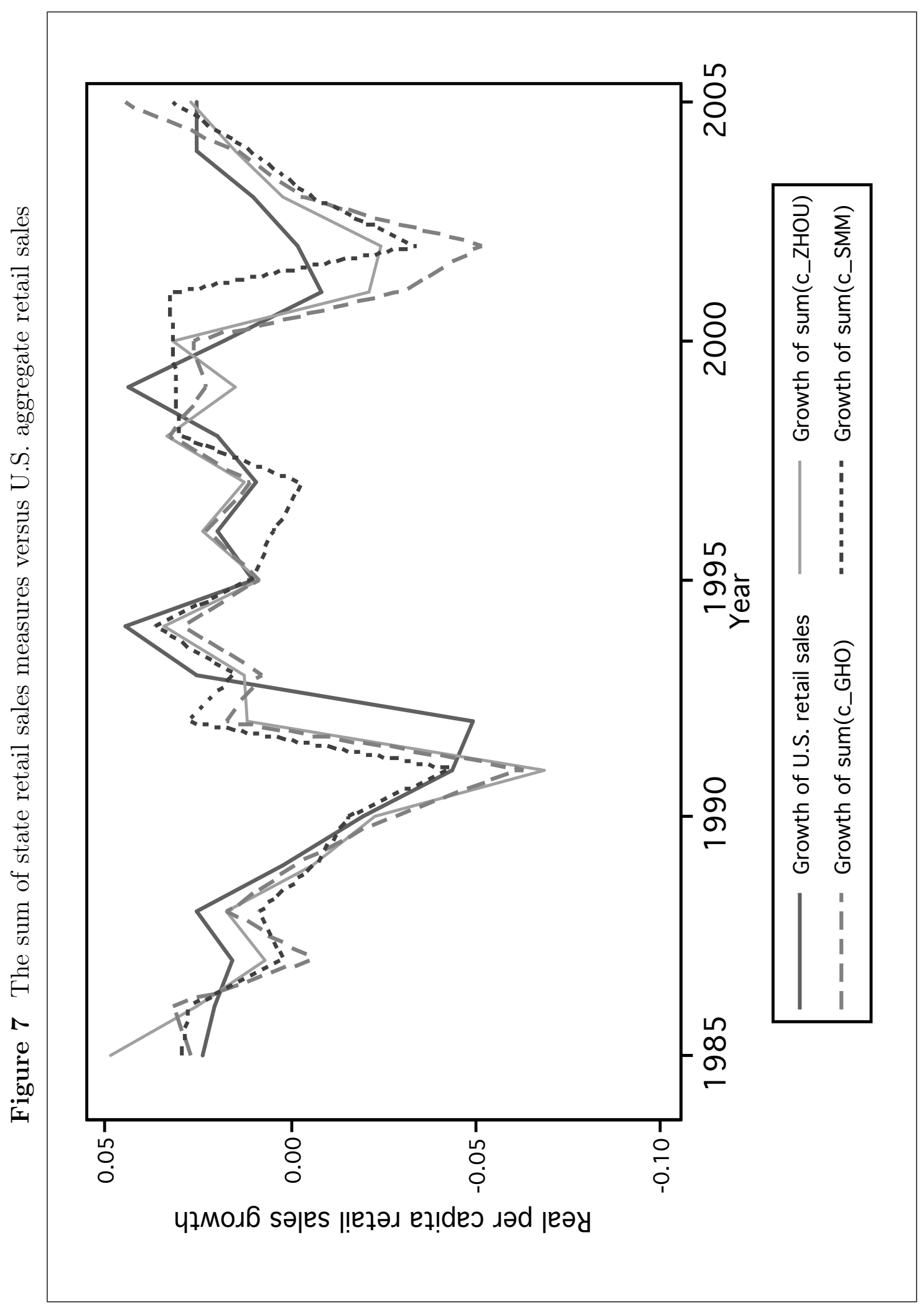




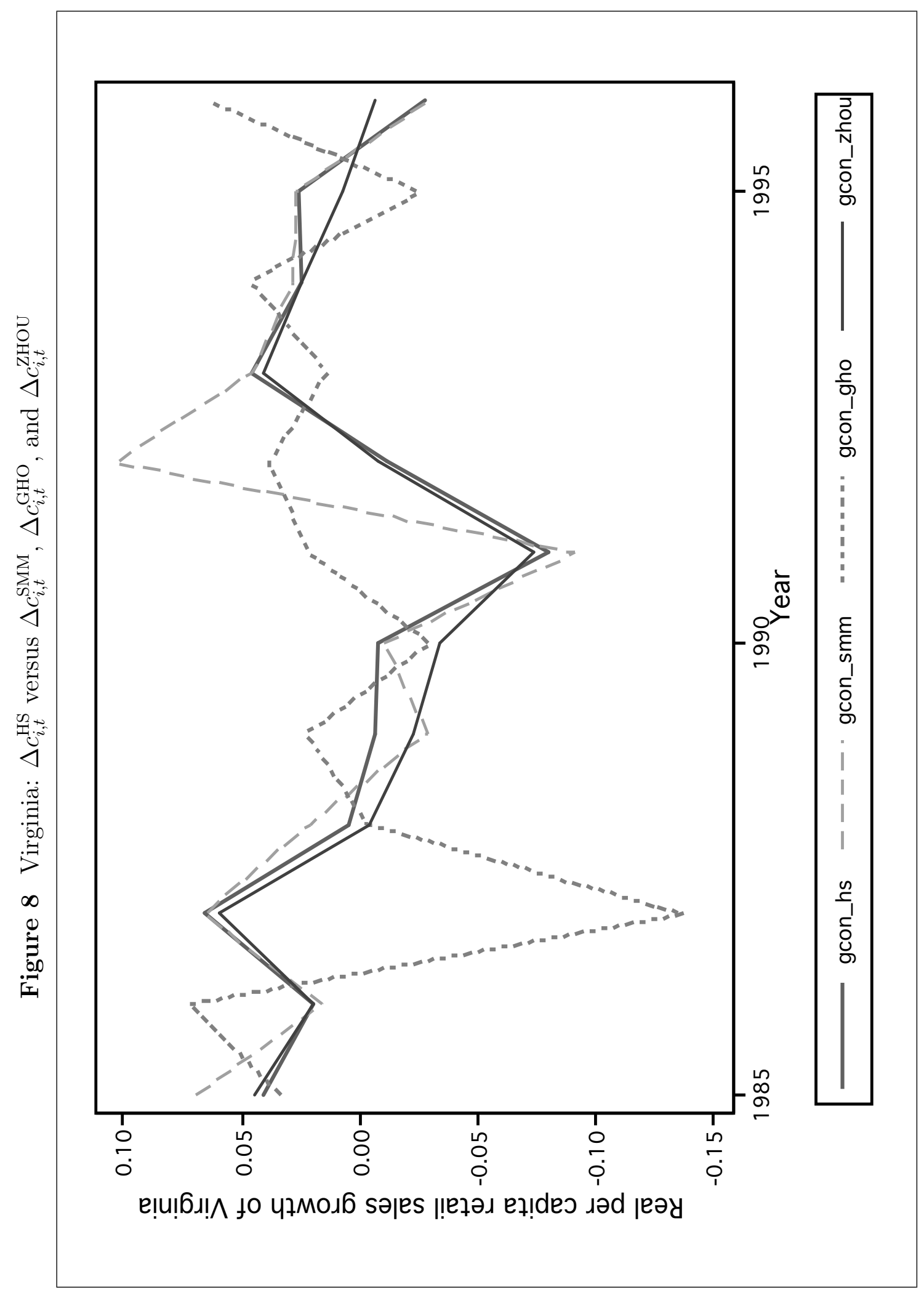




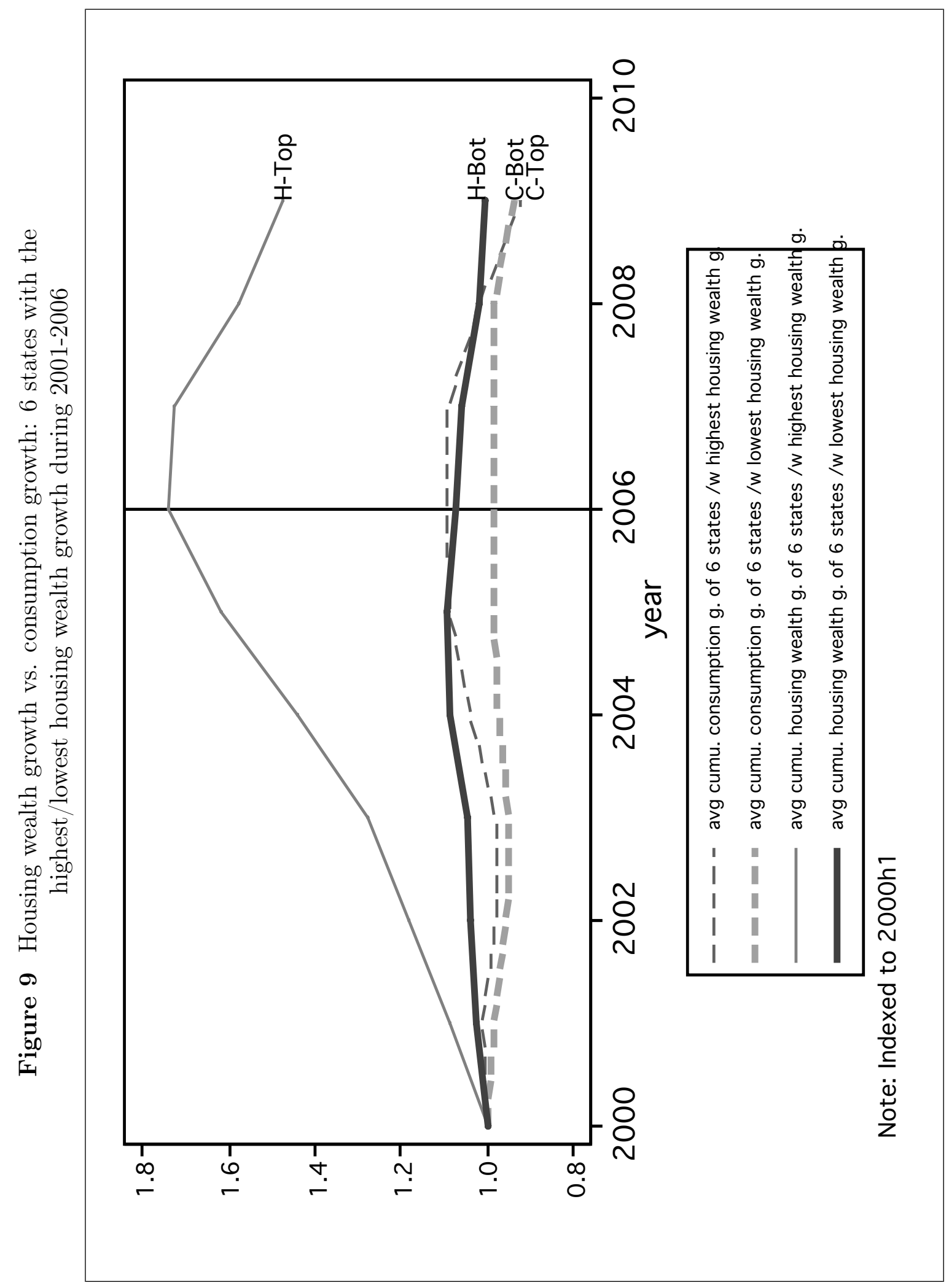




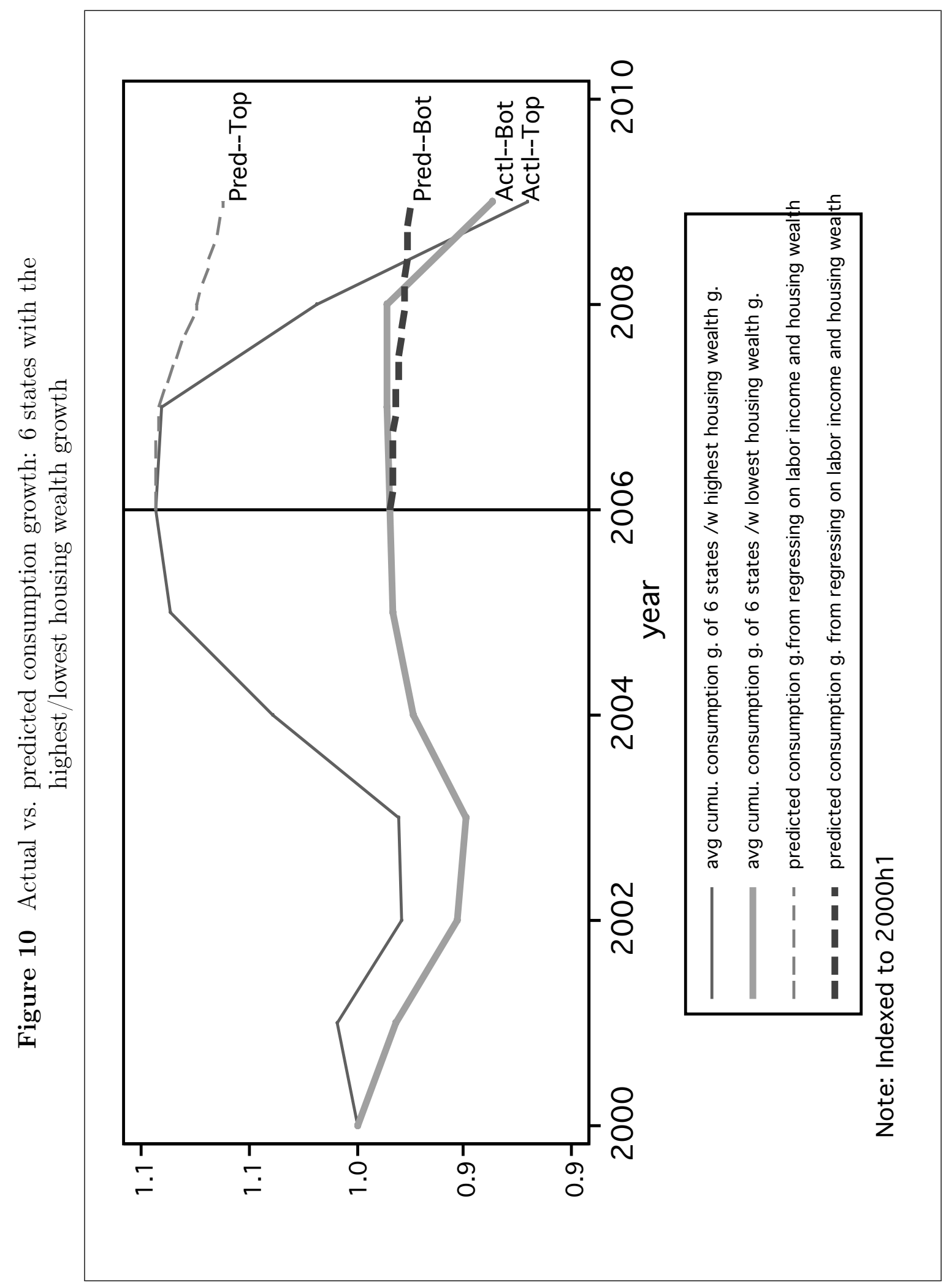


Table 1 Data Summary

\begin{tabular}{lccccc}
\hline \hline Variable & Obs & Mean & Std. Dev. & Min & Max \\
\hline$\Delta w_{i, t}^{f}$ & 180 & 0.002 & 0.130 & -0.379 & 0.212 \\
$\Delta w_{i, t}^{h} \Delta c_{i, t}$ & 180 & 0.055 & 0.050 & -0.027 & 0.227 \\
Best & 48 & 0.010 & 0.040 & -0.067 & 0.119 \\
Good $\Delta c_{i, t}$ & 180 & 0.003 & 0.042 & -0.095 & 0.099 \\
Combined $\Delta c_{i, t}$ & 180 & 0.007 & 0.067 & -0.321 & 0.428 \\
& & & & & \\
\hline
\end{tabular}

Table 2 Other retail sales measures vs. the benchmark

\begin{tabular}{lccc}
\hline \hline & $\operatorname{Avg} \Delta c_{i, t}^{*}-\Delta c_{i, t}^{\mathrm{HS}}$ & $\operatorname{Avg}\left|\Delta c_{i, t}^{*}-\Delta c_{i, t}^{\mathrm{HS}}\right|$ & Std. Dev. $\Delta c_{i, t}^{*}-\Delta c_{i, t}^{\mathrm{HS}}$ \\
$\Delta c_{i, t}^{\mathrm{SMM}}$ & 0.001 & 0.015 & 0.027 \\
$\Delta c_{i, t}^{\mathrm{GHO}}$ & 0.0007 & 0.045 & 0.069 \\
$\Delta c_{i, t}^{\mathrm{ZHOU}}$ & 0.0007 & 0.040 & 0.062 \\
\hline \hline
\end{tabular}


Table 3 Data description: $\Delta c_{i, t}=\alpha_{t}+\beta_{1} \Delta y_{i, t}+\beta_{2} \Delta w_{i, t}^{f}+\beta_{3} \Delta w_{i, t}^{h}$

Best Data

\begin{tabular}{lccccccc}
\hline \hline & $(1)$ & $(2)$ & $(3)$ & $(4)$ & $(5)$ & $(6)$ & $(7)$ \\
$\Delta y_{i, t}$ & $0.766^{* * *}$ & & & $0.681^{* * *}$ & $0.762^{* * *}$ & & $0.665^{* * *}$ \\
& $(0.204)$ & & & $(0.202)$ & $(0.18)$ & & $(0.175)$ \\
$\Delta w_{i, t}^{f}$ & & $0.431^{* *}$ & & $0.352^{* *}$ & & $0.475^{* * *}$ & $0.397^{* *}$ \\
& & $(0.176)$ & & $(0.176)$ & & $(0.162)$ & $(0.162)$ \\
$\Delta w_{i, t}^{h}$ & & & $0.145^{* *}$ & & $0.143^{* *}$ & $0.162^{* *}$ & $0.158^{* * *}$ \\
& & & $(0.066)$ & & $(0.061)$ & $(0.063)$ & $(0.06)$ \\
Obs. & 48 & 48 & 48 & 48 & 48 & 48 & 48 \\
$\bar{R}^{2}$ & 0.72 & 0.701 & 0.696 & 0.739 & 0.747 & 0.736 & 0.774 \\
Partial $\bar{R}^{2}$ & 0.154 & 0.095 & 0.079 & 0.212 & 0.236 & 0.202 & 0.318 \\
\hline \hline
\end{tabular}

Good Data

\begin{tabular}{|c|c|c|c|c|c|c|c|}
\hline$\Delta y_{i, t}$ & $\begin{array}{c}(1) \\
1.009^{* * *} \\
(0.246)\end{array}$ & $\overline{(2)}$ & 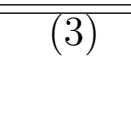 & $\begin{array}{c}(4) \\
0.989^{* * *} \\
(0.251)\end{array}$ & $\begin{array}{c}(5) \\
0.971^{* * *} \\
(0.254)\end{array}$ & $\overline{(26)}$ & $\begin{array}{c}(7) \\
0.956^{* * *} \\
(0.258)\end{array}$ \\
\hline$\Delta w_{i, t}^{f}$ & & $\begin{array}{l}0.112 \\
(0.086)\end{array}$ & & $\begin{array}{l}0.059 \\
(0.085)\end{array}$ & & $\begin{array}{l}0.095 \\
(0.086)\end{array}$ & $\begin{array}{l}0.053 \\
(0.085)\end{array}$ \\
\hline$\Delta w_{i, t}^{h}$ & & & $\begin{array}{c}0.093^{*} \\
(0.055)\end{array}$ & & $\begin{array}{l}0.039 \\
(0.053)\end{array}$ & $\begin{array}{l}0.086 \\
(0.055)\end{array}$ & $\begin{array}{l}0.036 \\
(0.054)\end{array}$ \\
\hline Obs. & 180 & 180 & 180 & 180 & 180 & 180 & 180 \\
\hline $\bar{R}^{2}$ & 0.261 & 0.188 & 0.194 & 0.258 & 0.259 & 0.194 & 0.256 \\
\hline Partial $\bar{R}^{2}$ & 0.091 & 0.002 & 0.009 & 0.088 & 0.088 & 0.009 & 0.085 \\
\hline \multicolumn{8}{|c|}{ Combined Data } \\
\hline$\Delta y_{i, t}$ & $\begin{array}{c}(1) \\
1.054^{* * *} \\
(0.21)\end{array}$ & $\overline{(2)}$ & (3) & $\begin{array}{c}(4) \\
1.028^{* * *} \\
(0.21)\end{array}$ & $\begin{array}{c}(5) \\
0.983^{* * *} \\
(0.216)\end{array}$ & $(6)$ & $\begin{array}{c}(7) \\
0.964^{* * *} \\
(0.217)\end{array}$ \\
\hline$\Delta w_{i, t}^{f}$ & & $\begin{array}{l}0.131 \\
(0.083)\end{array}$ & & $\begin{array}{l}0.076 \\
(0.078)\end{array}$ & & $\begin{array}{l}0.107 \\
(0.082)\end{array}$ & $\begin{array}{l}0.065 \\
(0.078)\end{array}$ \\
\hline$\Delta w_{i, t}^{h}$ & & & $\begin{array}{c}0.128^{* *} \\
(0.05)\end{array}$ & & $\begin{array}{l}0.074 \\
(0.049)\end{array}$ & $\frac{0.121^{* *}}{(0.05)}$ & $\begin{array}{c}0.07 \\
(0.049)\end{array}$ \\
\hline Obs. & 180 & 180 & 180 & 180 & 180 & 180 & 180 \\
\hline $\bar{R}^{2}$ & 0.368 & 0.287 & 0.301 & 0.368 & 0.372 & 0.303 & 0.371 \\
\hline Partial $\bar{R}^{2}$ & 0.12 & 0.007 & 0.027 & 0.12 & 0.126 & 0.03 & 0.124 \\
\hline
\end{tabular}

a. Partial $\bar{R}^{2}$ refers to the proportion of variance explained by all variables other than the year dummies.

b. Standard errors in parenthesis. $\left\{{ }^{*},{ }^{*},{ }^{* * *}\right\}=$ significant at the $\{10 \%, 5 \%, 1 \%\}$ level. 
Table 4 Data description - COS method: $\Delta \tilde{c}_{i, t}=\alpha_{t}+\beta_{1} \Delta \tilde{y}_{i, t}+\beta_{2} \Delta \tilde{w}_{i, t}^{f}+\beta_{3} \Delta \tilde{w}_{i, t}^{h}$

\begin{tabular}{lccc}
\hline \hline & Best Data & Good Data & Combined Data \\
\hline$\Delta y_{i, t}$ & $0.844^{* * *}$ & $1.305^{* * *}$ & $1.368^{* * *}$ \\
& $(0.271)$ & $(0.415)$ & $(0.383)$ \\
$\Delta w_{i, t}^{f}$ & $0.07^{* * *}$ & 0.029 & $0.034^{*}$ \\
& $(0.021)$ & $(0.021)$ & $(0.02)$ \\
$\Delta w_{i, t}^{h}$ & $0.017^{*}$ & 0.007 & 0.004 \\
$\beta_{2}=\beta_{3}$ & $(0.01)$ & $(0.01)$ & $(0.009)$ \\
& 6.346 & 0.756 & 1.526 \\
Obs. & (Rejected) & (Accepted) & $($ Accepted) \\
$\bar{R}^{2}$ & 48 & 180 & 180 \\
Partial $\bar{R}^{2}$ & 0.783 & 0.247 & 0.349 \\
\hline \hline
\end{tabular}

Table $5 \quad \Delta \tilde{c}_{i, t}=\alpha_{t}+\beta_{1} \Delta \tilde{y}_{i, t-2}+\beta_{2} \Delta \tilde{w}_{i, t-2}^{f}+\beta_{3} \Delta \tilde{w}_{i, t-2}^{h}$

\begin{tabular}{lccc}
\hline \hline & Best Data & Good Data & Combined Data \\
\hline$\Delta y_{i, t-2}$ & 0.474 & $0.787^{* *}$ & $0.884^{* * *}$ \\
& $(0.503)$ & $(0.38)$ & $(0.332)$ \\
$\Delta w_{i, t-2}^{f}$ & -.021 & -.004 & -.004 \\
& $(0.033)$ & $(0.026)$ & $(0.025)$ \\
$\Delta w_{i, t-2}^{h}$ & 0.046 & $0.058^{* * *}$ & $0.047^{* *}$ \\
$\beta_{2}=\beta_{3}$ & $(0.041)$ & $(0.021)$ & $(0.02)$ \\
& 2.168 & 4.458 & 3.603 \\
Obs. & $($ Accepted $)$ & (Rejected) & $($ Accepted) \\
$\bar{R}^{2}$ & 24 & 90 & 90 \\
Partial $\bar{R}^{2}$ & 0.197 & 0.094 & 0.132 \\
\hline \hline
\end{tabular}

Table 6 Habit formation: $\Delta \tilde{c}_{i, t}=\alpha_{t}+\lambda E_{t-2} \Delta \tilde{c}_{i, t-1}+\varepsilon_{t}$

\begin{tabular}{lccc}
\hline \hline & Best Data & Good Data & Combined Data \\
\hline$E_{t-2} \Delta \tilde{c}_{i, t-1}{ }^{16}$ & 0.422 & -.122 & -.014 \\
& $(0.336)$ & $(0.253)$ & $(0.275)$ \\
obs & 24 & 90 & 90 \\
$\bar{R}^{2}$ & 0.156 & -0.019 & 0.001 \\
First Stage: & & & \\
Partial $R^{2}$ & 0.344 & 0.148 & 0.146 \\
$P-$ val & 0.092 & 0.009 & 0.01 \\
\hline \hline
\end{tabular}


Table 7 Data description using data up to 2009: $\Delta c_{i, t}=\alpha_{t}+\beta_{1} \Delta y_{i, t}+\beta_{2} \Delta w_{i, t}^{h}$ Best Data

\begin{tabular}{lccc}
\hline \hline & $(1)$ & $(2)$ & $(3)$ \\
\hline$\Delta y_{i, t}$ & $1.540^{* * *}$ & & $1.226^{* * *}$ \\
& $(0.351)$ & $(0.3)$ \\
$\Delta w_{i, t}^{h}$ & & $0.318^{* * *}$ & $0.232^{* * *}$ \\
& & $(0.07)$ & $(0.06)$ \\
obs. & 96 & 96 & 96 \\
$\bar{R}^{2}$ & 0.657 & 0.635 & 0.704 \\
Partial $\bar{R}^{2}$ & 0.262 & 0.214 & 0.364 \\
F-Test & 5.275 & 5.73 & 1.875 \\
P-Val & 0.024 & 0.019 & 0.16 \\
\hline \hline
\end{tabular}

Good Data

\begin{tabular}{lccc}
\hline \hline & $(1)$ & $(2)$ & $(3)$ \\
\hline$\Delta y_{i, t}$ & $1.588^{* * *}$ & & $1.533^{* * *}$ \\
$\Delta w_{i, t}^{h}$ & $(0.281)$ & $0.181^{* * *}$ & $(0.285)$ \\
& & $(0.063)$ & 0.047 \\
obs. & & 360 & $(0.059)$ \\
$\bar{R}^{2}$ & 360 & 0.263 & 360 \\
Partial $\bar{R}^{2}$ & 0.349 & 0.021 & 0.349 \\
F-Test & 0.136 & 1.908 & 0.135 \\
P-Val & 3.722 & 0.168 & 1.804 \\
\hline \hline
\end{tabular}

Combined Data

\begin{tabular}{lccc}
\hline \hline & $(1)$ & $(2)$ & $(3)$ \\
\hline$\Delta y_{i, t}$ & $\begin{array}{c}1.688^{* * *} \\
(0.256)\end{array}$ & & $1.631^{* * *}$ \\
$\Delta w_{i, t}^{h}$ & & $0.192^{* * *}$ & $(0.262)$ \\
& & $(0.056)$ & 0.05 \\
obs. & 360 & 360 & $(0.051)$ \\
$\bar{R}^{2}$ & 0.444 & 0.339 & 360 \\
Partial $\bar{R}^{2}$ & 0.183 & 0.029 & 0.443 \\
F-Test & 5.574 & 1.263 & 0.183 \\
P-Val & 0.019 & 0.262 & 2.839 \\
\hline \hline
\end{tabular}

a. Partial $\bar{R}^{2}$ refers to the proportion of variance explained by all variables other than the year dummies.

b. Standard errors in parenthesis. $\{*, * *, * * *\}=$ significant at the $\{10 \%, 5 \%, 1 \%\}$ level.

c. F-Test and P-val is for the test of equal income and house wealth effect for the periods before and after 2005. 
Table 8 Data Description using data up to 2009 - COS Method:

$$
\Delta \tilde{c}_{i, t}=\alpha_{t}+\beta_{1} \Delta \tilde{y}_{i, t}+\beta_{2} \Delta \tilde{w}_{i, t}^{h}
$$

\begin{tabular}{lccc}
\hline \hline & Best Data & Good Data & Combined Data \\
\hline$\Delta y_{i, t}$ & $1.554^{* * *}$ & $2.088^{* * *}$ & $2.230^{* * *}$ \\
& $(0.426)$ & $(0.536)$ & $(0.518)$ \\
$\Delta w_{i, t}^{h}$ & $0.031^{* * *}$ & 0.005 & 0.006 \\
& $(0.009)$ & $(0.01)$ & $(0.008)$ \\
Obs. & 96 & 360 & 360 \\
$\bar{R}^{2}$ & 0.674 & 0.3 & 0.382 \\
Partial $\bar{R}^{2}$ & 0.248 & 0.105 & 0.136 \\
F-Test & 9.96 & 8.673 & 9.941 \\
P-Val & 0.0001 & 0.0002 & 0.00006 \\
\hline \hline
\end{tabular}

Table 9 Wealth Effect using data up to 2009: $\Delta \tilde{c}_{i, t}=\alpha_{t}+\beta_{1} \Delta \tilde{y}_{i, t-2}+\beta_{2} \Delta \tilde{w}_{i, t-2}^{h}$

\begin{tabular}{lccc}
\hline \hline & Best Data & Good Data & Combined Data \\
\hline$\Delta y_{i, t-2}$ & -.709 & 0.792 & 0.647 \\
$\Delta w_{i, t-2}^{h}$ & $(0.432)$ & $(0.698)$ & $(0.686)$ \\
& -.026 & -.011 & -.006 \\
Obs. & $(0.018)$ & $(0.016)$ & $(0.014)$ \\
$\bar{R}^{2}$ & 72 & 270 & 270 \\
Partial $\bar{R}^{2}$ & 0.55 & 0.209 & 0.267 \\
F-Test & 0.047 & 0.007 & 0.003 \\
P-Val & 3.187 & 4.619 & 3.731 \\
\hline \hline
\end{tabular}

a. Partial $\bar{R}^{2}$ refers to the proportion of variance explained by all variables other than the year dummies.

b. Standard errors in parenthesis. $\{*, * *, * * *\}=$ significant at the $\{10 \%, 5 \%, 1 \%\}$ level.

c. F-Test and P-val is for the test of equal income and house wealth effect for the periods before and after 2005 .

Table 10 Actual $\Delta c_{i, t}$ vs. predicted $\Delta c_{i, t}$ for top and bottom states

\begin{tabular}{|c|c|c|c|c|c|}
\hline & Year & $\begin{array}{c}\text { Index of } \\
\text { actl. } c\end{array}$ & $\begin{array}{c}\text { Index of } \\
\text { pred. } c\end{array}$ & actl. $\Delta c_{i, t}$ & pred. $\Delta c_{i, t}$ \\
\hline \multirow{4}{*}{ Top States } & 2006 & 1.094 & 1.094 & & \\
\hline & 2007 & 1.091 & 1.093 & $-0.3 \%$ & $-0.1 \%$ \\
\hline & 2008 & 1.019 & 1.074 & $-6.6 \%$ & $-1.7 \%$ \\
\hline & 2009 & 0.920 & 1.062 & $-9.7 \%$ & $-1.2 \%$ \\
\hline \multirow{4}{*}{ Bot States } & 2006 & 0.984 & 0.984 & & \\
\hline & 2007 & 0.986 & 0.982 & $0.2 \%$ & $-0.2 \%$ \\
\hline & 2008 & 0.986 & 0.978 & $0.0 \%$ & $-0.4 \%$ \\
\hline & 2009 & 0.937 & 0.976 & $-4.9 \%$ & $-0.2 \%$ \\
\hline
\end{tabular}




\section{APPENDIX}

\section{A Stock Wealth Data}

The data used in this paper were constructed during the author's part-time employment at a private company over two years. All financial data feeds are provided as anonymous, ZIP +4 Code data by product type. Absolutely no non-public, personally identifiable information on U.S. households have been used in this study.

Once the $\mathrm{ZIP}+4$ Code level data is received by the private company, for $\mathrm{ZIP}+4$ codes with fewer than 7 households, the data are joined and averaged with other $\mathrm{ZIP}+4$ Codes to ensure a minimum household count of 7 per $\mathrm{ZIP}+4$ code. The average value is then imputed identically back down to the affected ZIP +4 Codes. The rules utilized to perform the joining and averaging are complex and based on geographical proximity and other factors.

The names of the financial institutions reporting to the private company are suppressed and cannot be revealed. However, it should be noted that the number of reporting institutions changes over time. Hence, the biggest concern with constructing the stock wealth data is the possibility that the variations in wealth are caused by reasons other than the wealth holding variations of the state residents. To minimize this problem, we expended a great deal of effort keeping track of all mergers and institutions' membership in the network.

The formation of a consistent source of financial data over time was performed at the state level. Thus, I could construct a common group of reporting institutions for every TWO ADJACENT CYCLES. So the growth rates could be calculated as the log difference of two adjacent values on a rolling basis. Specifically speaking, for growth rate of stock wealth for state $i$ at time $t$, we summed up the assets by those institutions reporting at both $t$ and $t-1$ for state $i$, and then I took the log difference.

Specifically, suppose $F_{i, t}^{j}$ is the total amount of stock wealth reported at time $t$ for state $i$ by institution $j$. $\Omega_{i, t}$ is the set of all institutions reporting at time $t$ for state $i$. So $\Omega_{i, t} \bigcap \Omega_{i, t-1}$ is the set of all the institutions reporting for state $i$ at both time $t$ and $t-1$. Therefore, $\Delta F_{i, t}$, the growth rate of stock wealth of state $i$ at time $t$ is defined as:

$$
\Delta F_{i, t}=\ln \left(\sum_{j \in \Omega_{i, t} \cap \Omega_{i, t-1}} F_{i, t}^{j}\right)-\ln \left(\sum_{j \in \Omega_{i, t} \cap \Omega_{i, t-1}} F_{i, t-1}^{j}\right)
$$

where $i=1,2, \ldots, 51 ; t=2000 h 2,2001 h 1, \ldots, 2005 h 2$.

After obtaining the correct growth rates, total stock market wealth for each state were imputed backward as

$$
\begin{gathered}
\hat{F}_{i, T}=F_{i, T} \\
\hat{F}_{i, T-1}=\hat{F}_{i, T} / \exp \left(\Delta F_{i, T}\right)
\end{gathered}
$$




$$
\hat{F}_{i, T-2}=\hat{F}_{i, T-1} / \exp \left(\Delta F_{i, T-1}\right)
$$

where $F_{i, T}=\sum_{j \in \Omega_{i, T}} F_{i, T}^{j}$ and $T=2005 h 2$.

Real stock wealth per capita is defined as

$$
\hat{f}_{i, t}=\hat{F}_{i, t} /\left(C P I_{t} / P O P_{i, t}\right)
$$

where $C P I_{t}$ is the consumer price index at time $t$ and $P O P_{i, t}$ is the population of state $i$ at time $t$. Therefore, growth rate of real stock wealth per capita is calculated as:

$$
\Delta f_{i, t}=\ln \left(f_{i, t}\right)-\ln \left(f_{i, t-1}\right)
$$

\section{B Results using the elasticity method}

Many papers in the literature have estimated wealth effects by adopting the elasticity method. Consequently, we then investigate the respective housing wealth and stock wealth effects by estimating the following equation, as with most related studies:

$$
\Delta c_{i, t}=\alpha_{t}+\beta_{1} \Delta y_{i, t-2}+\beta_{2} \Delta w_{i, t-2}^{f}+\beta_{3} \Delta w_{i, t-2}^{h}+\varepsilon_{i, t} .
$$

Table 11 reports the regression results from Equation 13 for all three sets of consumption data. The findings are roughly consistent across the three datasets.

The most outstanding and robust finding is the large coefficient for lagged housing wealth. The stock wealth effects reported in Table 11 are all statistically insignificant. Furthermore, in 2 of the 3 estimations, the size of the stock wealth effect is economically small. The hypotheses of equal housing wealth and stock wealth coefficients are, however, accepted in 2 out of 3 estimations. 
Table 11 Results for the elasticity method

\begin{tabular}{lccc}
\hline \hline & Best Data & Good Data & Combined Data \\
\hline$\Delta y_{i, t-2}$ & 0.259 & 0.273 & $0.437^{* *}$ \\
$\Delta w_{i, t-2}^{f}$ & $(0.326)$ & $(0.288)$ & $(0.307)$ \\
$\Delta w_{i, t-2}^{h}$ & 0.267 & -.017 & -.020 \\
Test of $\beta_{2}=\beta_{3}$ & $(0.27)$ & $(0.078)$ & $(0.079)$ \\
& $0.398^{* *}$ & $0.246^{* *}$ & $0.237^{* * *}$ \\
Obs. & $(0.201)$ & $(0.099)$ & $(0.083)$ \\
$\bar{R}^{2}$ & 0.136 & 3.609 & 4.068 \\
Partial $\bar{R}^{2}$ & 24 & (Accepted) & 90 \\
\hline \hline
\end{tabular}




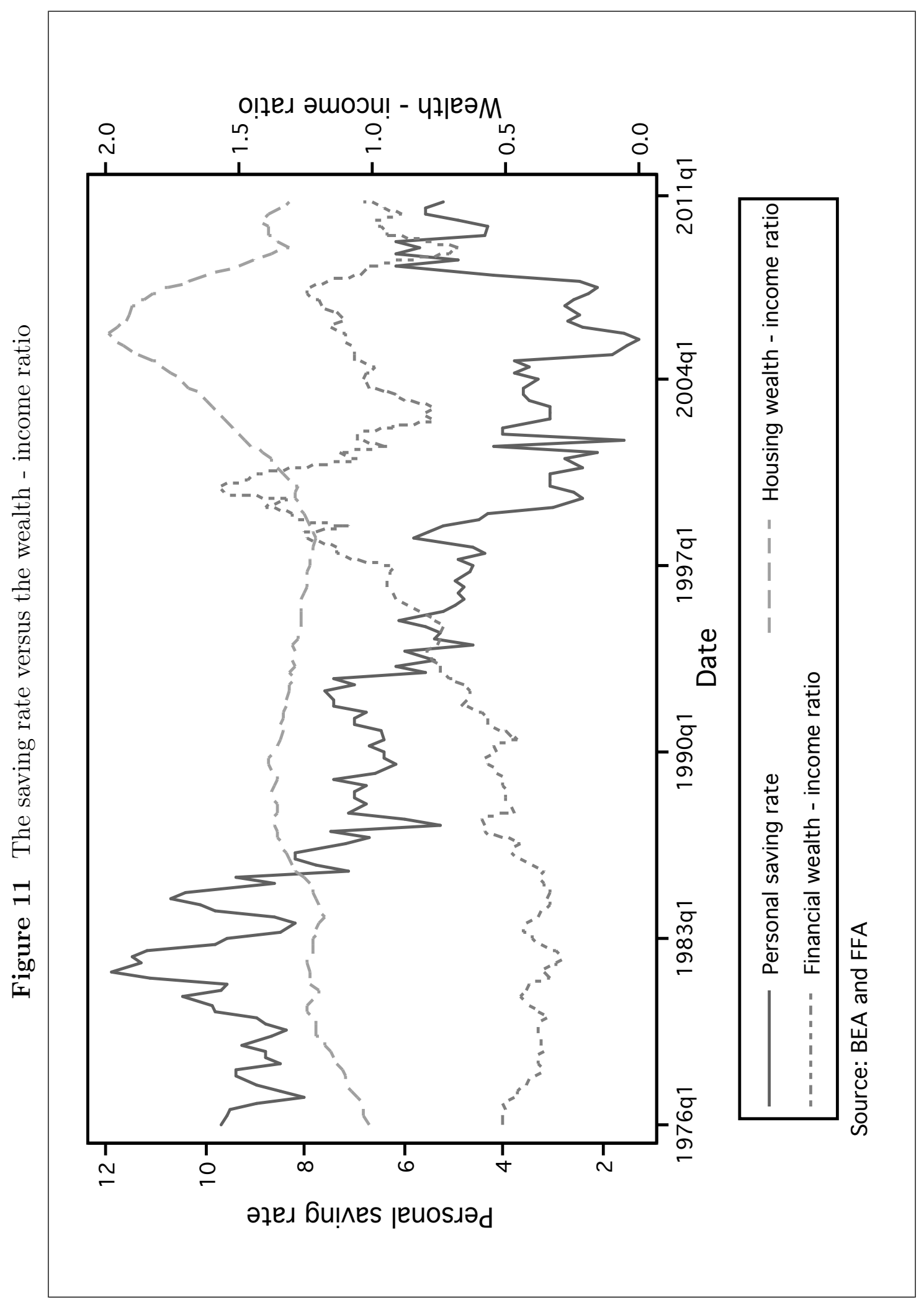




\section{References}

Antoniewicz, Rochelle L. (2000): "A Comparison of the Household Sector from the Flow of Funds Accounts and the Survey of," Discussion paper, Federal Reserve Board.

Aron, Janie, John V. Duca, John Muellbauer, Keiko Murata, And Anthony Murphy (2010): "Credit, Housing Collateral and Consumption: Evidence from the UK, Japan and the US," Working Paper 1002, Federal Reserve Bank of Dallas.

Aron, Janine, And John Muellbauer (2006): "Housing Wealth, Credit Conditions and Consumption," Centre for the Study of African Economies Series WPS 2006-08, University of Oxford.

Asdrubali, Pierfederico, Bent Sorensen, And Oved Yosha (1996): "Channels of interstate risksharing: United States 1963-1990," Quarterly Journal of Economics, 111, 1081-1110.

Attanasio, Orazio P., Laura Blow, Robert Hamilton, and Andrew Leicester (2009): "Booms and Busts: Consumption, House Prices and Expectations," Economica, 76(301), 20-50.

BAyOumi, TAmim, AND HALI EDISON (2003): "Is Wealth Increasingly Driving Consumption," DNB Staff Reports (discontinued) 101, Netherlands Central Bank.

Bertaut, Carol (2002): "Equity Prices, Household Wealth, and Consumption Growth in Foreign Industrial Countries: Wealth Effects in the 1990s," International Finance Discussion Papers 724, Board of Governors of the Federal Reserve System.

Bostic, Raphael, Stuart Gabriel, And Gary Painter (2009): "Housing Wealth, Financial Wealth, and Consumption: New Evidence from Micro Data," Regional Science and Urban Economics, 39, 79-89.

Byrne, Joseph P., And E. Philip Davis (2003): "Disaggregate Wealth and Aggregate Consumption: an Investigation of Empirical Relationships for the G7," Oxford Bulletin of Economics and Statistics, 65(2), 197-220.

Campbell, John Y., And Joao F. Cocco (2007): "How Do House Prices Affect Consumption? Evidence From Micro Data," Journal of Monetary Economics, 54(3), 591-621.

Campbell, John Y., And N. Gregory Mankiw (1989): "Consumption, Income and Interest Rates: Reinterpreting the Time Series Evidence," in NBER 
Macroeconomics Annual, ed. by Olivier J. Blanchard, and Stanley Fischer, Cambridge, MA. MIT Press.

Cardarelli, Roberto, Deniz Igan, and Alessandro Rebucci (2008): "The Changing Housing Cycle and the Implications for Monetary Policy," in World Economic Outlook, chap. 3. Washington: International Monetary Fund.

Carroll, Christopher D., Misuzu Otsuka, And Jiri Slacalek (2011): "How Large Are Housing and Financial Wealth Effects? A New Approach," Journal of Money, Credit and Banking, 43(1), 55-79, http: //econ.jhu.edu/people/ccarroll/papers/cosWealthEffects/.

Case, Karl E., John M. Quigley, And Robert J. Shiller (2005): "Comparing Wealth Effects: The Stock Market versus The Housing Market," Advances in Macroeconomics, 5(1), 1-34.

_ (2011): "Wealth Effects Revisited 1978-2009," Cowles foudation discussion paper, Cowles Foundaion for Reserch in Economics, Yale University.

Ciccone, Antonio (2002): "Agglomeration effects in Europe," European Economic Review, 46(2), 213-227.

Ciccone, Antonio, And Robert E. Hall (1996): "Productivity and the Density of Economic Activity," The American Economic Review, 86(1), 54-70.

Davis, Morris, And Michael Palumbo (2001a): "A Primer on the Economics and Time Series Econometrics of Wealth Effects," Federal Reserve Board Finance and Economics Discussion Papers 2001-09.

Davis, Morris, And Michael G. Palumbo (2001b): "Does Stock Market Wealth Matter for Consumption?," Finance and Economics Discussion Series 2001-23. Washington: Board of Governors of the Federal Reserve System.

Del Negro, Marco (1998): "Aggregate Risk Sharing Across US States and Across European Countries," Ph.D. thesis, Yale University.

Disney, Richard, John Gathergood, And Andrew Henley (2010): "House Price Shocks, Negative Equity, and Household Consumption in the United Kingdom," Journal of the European Economic Association, 8(6), 1179-1207.

Disney, Richard, Andrew Henley, And David Jevons (2003): "House Price Shocks, Negative Equity and Household Consumption in the UK in the 1990s," memo, University of Nottingham. 
Dvornak, Nikola, And Marion Kohler (2003): "Housing Wealth Stock Market Wealth and Consumption: A Panel Analysis for Australia," RBA Research Discussion Papers rdp2003-07, Reserve Bank of Australia.

Dynan, Karen E., And Dean M. Maki (2001): "A Primer on the Economics and Time Series Econometrics of Wealth Effects," Finance and Economics Discussion Series 2001-9. Washington: Board of Governors of the Federal Reserve System.

Edelstein, Robert H., And SAu Kim Lum (2004): "House prices, wealth effects, and the Singapore macroeconomy," Journal of Housing Economics, 13, 342-367.

Garrett, Thomas A., Rubèn Hernàndez-Murillo, and Michael T. Owyang (2004): "Does Consumer Sentiment Predict Regional Consumption?," Federal Reserve Bank of St. Louis Review, 87(2), 123-35.

Girouard, Nathalie, And Sveinbjörn BlÖndal (2001): "House Prices and Economic Activity," OECD Economics Department Working Papers 279, OECD Economics Department.

Glaeser, Edward L, Hedi D. Kallal, Jose A. Scheinkman, and Andrei Shleifer (1992): "Growth in Cities," Journal of Political Economy, 100(6), 112652.

HAll, RoBert E (1978): "Stochastic Implications of the Life Cycle-Permanent Income Hypothesis: Theory and Evidence," Journal of Political Economy, 86(6), $971-87$.

Kennickell, Arthur B. (2003): "A Rolling Tide: Changes in the Distribution of Wealth in the U.S., 1989-2001," Discussion paper, Federal Reserve Board, http://www.federalreserve.gov/pubs/oss/oss2/papers/concentration.2004.5.pdf.

Lettau, Martin, And Sydney Ludvigson (2001): "Consumption, Aggregate Wealth and Expected Stock Returns," Journal of Finance, LVI(3), 815-849.

- (2004): "Understanding Trend and Cycle in Asset Values: Reevaluating the Wealth Effect on Consumption," American Economic Review, 94(1), 279-299.

Levin, Laurence (1998): "Are assets fungible? Testing the behavioral theory of life-cycle savings," Journal of Economic Organization and Behavior, , 36, 59-83.

Lopez, Miguel Angel Garcia, And Ivan Muniz Olivera (2005): "The Spatial Effect of Intra-Metropolitan Agglomeration Economies," Working Papers 0513, Department of Applied Economics at Universitat Autonoma of Barcelona. 
Ludwig, Alexander, And Torsten Sløk (2002): "The Impact of Changes in Stock Prices and House Prices on Consumption in OECD Countries," Working Paper 02/1 International Monetary Fund.

Mian, Atif, And Amir Sufi (2010): "The Effects of Fiscal Stimulus: Evidence from the 2009 'Cash for Clunkers' Program," Discussion paper, National Bureau of Economic Research.

(2011): "Consumers and the Economy, Part II: Household Debt and the Weak U.S. Recovery," FRBSF Economic Letter, 4.

Shiller, Robert J. (2004): "Household Reaction to Chagnes in Housing Wealth," Discussion paper, Cowles Foundation for Research in Economics, Yale University, Discussion Paper NO. 1459.

Thaler, Richard H. (1990): "Anomalies: Saving, Fungibility, and Mental Accounts," Journal of Economic Perspectives, 4(1), 193-205.

Wilcox, David W. (1992): "The Construction of U.S. Consumption Data: Some Facts and Their Implications for Empirical Work," The American Economic Review, 82(4), 922-941.

Zhou, Xia (2010): "Essays On U.S. State-Level Financial Wealth Data and Consumption Data," Ph.D. thesis, Johns Hopkins University, http://jhir.library.jhu.edu/handle/1774.2/34267. 